\title{
Establishing anaerobic hydrocarbon-degrading enrichment cultures of microorganisms under strictly anoxic conditions
}

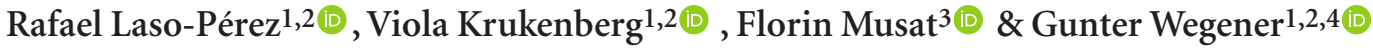 \\ ${ }^{1}$ Max-Planck Institute for Marine Microbiology, Bremen, Germany. ${ }^{2}$ Alfred Wegener Institute, Helmholtz Centre for Polar and Marine Research, Bremerhaven, Germany. \\ ${ }^{3}$ Helmholtz Centre for Environmental Research - UFZ, Leipzig, Germany. ${ }^{4}$ MARUM, Center for Marine Environmental Sciences, University of Bremen, Bremen, \\ Germany. Correspondence should be addressed to G.W. (gwegener@mpi-bremen.de).
}

Published online 17 May 2018; doi:10.1038/nprot.2018.030

\begin{abstract}
Traditionally, the description of microorganisms starts with their isolation from an environmental sample. Many environmentally relevant anaerobic microorganisms grow very slowly, and often they rely on syntrophic interactions with other microorganisms. This impedes their isolation and characterization by classic microbiological techniques. We developed and applied an approach for the successive enrichment of syntrophic hydrocarbon-degrading microorganisms from environmental samples. We collected samples from microbial mat-covered hydrothermally heated hydrocarbon-rich sediments of the Guaymas Basin and mixed them with synthetic mineral medium to obtain sediment slurries. Supplementation with defined substrates (i.e., methane or butane), incubation at specific temperatures, and a regular maintenance procedure that included the measurement of metabolic products and stepwise dilutions enabled us to establish highly active, virtually sediment-free enrichment cultures of actively hydrocarbondegrading communities in a 6-months to several-years' effort. Using methane as sole electron donor shifted the originally highly diverse microbial communities toward defined mixed cultures dominated by syntrophic consortia consisting of anaerobic methane-oxidizing archaea (ANME) and different sulfate-reducing bacteria. Cultivation with butane at $50{ }^{\circ} \mathrm{C}$ yielded consortia of archaea belonging to Candidatus Syntrophoarchaeum and Candidatus Desulfofervidus auxilii partner bacteria. This protocol also describes sampling for further molecular characterization of enrichment cultures by fluorescence in situ hybridization (FISH), and transcriptomics and metabolite analyses, which can provide insights into the functioning of hydrocarbon metabolism in archaea and resolve important mechanisms that enable electron transfer to their sulfate-reducing partner bacteria.
\end{abstract}

\section{INTRODUCTION}

The emergence of massive parallel sequencing of phylogenetic marker genes and environmental metagenomics has markedly increased the known microbial diversity, yet most of the discovered organisms remain uncultured. The isolation of a microorganism from its environment is often precluded by slow growth, low abundance and complex interspecies dependencies. Thus, the metabolic potential and function of microbial communities are often assessed directly in environmental samples using culture-independent approaches ${ }^{1}$. However, resolving the physiology and environmental role of a microorganism, demands its accessibility for laboratory-based experiments under defined conditions. Classically, a target microorganism is isolated from the environment on a specific substrate using techniques such as dilution to extinction and streaking, thereby attempting to yield a clonal strain for physiological analysis ${ }^{2}$. Although this is often successful for rapidly growing microorganisms (e.g., doubling times of minutes to hours), it becomes difficult for those with lower growth rates or impossible for those that require a syntrophic partner. Therefore, the establishment of microbial enrichment cultures dominated by a few species offers an alternative approach for studying organisms not isolated in axenic cultures ${ }^{3}$. Circumventing the need for isolation, enriched microorganisms can be studied by culture-dependent microbiological techniques combined with culture-independent approaches ${ }^{4,5}$.

The concept of microbial enrichment cultures dates back more than a century to the work of Winogradsky and Beijerinck ${ }^{6,7}$. To establish a microbial enrichment culture, an environmental sample is incubated under conditions chosen to select microorganisms with defined physiological traits ${ }^{8}$. For instance, microorganisms performing a certain process, such as the anaerobic degradation of hydrocarbons, can be enriched by diluting a suitable environmental sample in defined growth medium and providing the model hydrocarbon as the sole substrate ${ }^{9}$. Tracking the consumption of the supplied substrates and/or the electron acceptor (e.g., nitrate, nitrite, sulfate or dissolved inorganic carbon), or the accumulation of reduced products, enables monitoring of metabolic activity, which serves as proxy for the progress of enriching for microorganisms with the desired metabolism. Steadily increasing substrate turnover rates and decreasing microbial diversity characterize a successful enrichment process. Enrichment cultures, as opposed to pure cultures (i.e., isolates), contain a multispecies community that is not necessarily stable in its composition over time ${ }^{10}$, hence regular controls on community composition are important. However, very often the enrichment of a microorganism is the initial step toward its eventual isolation ${ }^{11}$.

Marine and terrestrial subsurface sediments host large amounts of hydrocarbons that are biologically produced or result from the thermal decay of organic matter in sediments ${ }^{12}$. Gaseous hydrocarbons such as methane migrate via diffusion into sulfate-rich sediment layers. Here microorganisms oxidize methane with sulfate as electron acceptor, resulting in defined sulfate-methane interfaces ${ }^{13}$. Cold seeps and hot vents are submarine geological structures that emit fluids from the subsurface into the water column. These fluids are strongly reduced and often carry large 
amounts of hydrocarbons ${ }^{14-16}$. In the sediments, hydrocarbon seepage fuels vital microbial communities that thrive on the oxidation of methane and other hydrocarbons coupled to the reduction of sulfate ${ }^{17-19}$. The in vitro enrichment of anaerobic hydrocarbon oxidizers and their subsequent molecular characterization have been essential to the understanding of the microbial degradation of hydrocarbons in anoxic environments ${ }^{5,19-26}$. In general, isolation of anaerobic hydrocarbon degraders in pure culture is challenging due to slow growth, poor hydrocarbon solubility in water leading to mass-transfer limitations, and trophic dependencies. For the anaerobic oxidation of methane, which is carried out by archaea that are strictly dependent on metabolic interactions with sulfate-reducing bacteria ${ }^{5,18,27}$, isolation of the responsible organisms into pure culture has so far not been achieved. Therefore, advancement in the field was largely dependent on the successful establishment of enrichment cultures. Investigations of enrichment cultures have also been key in understanding the anaerobic bacterial or archaeal oxidation of short-chain gaseous alkanes $\left(\mathrm{C}_{2}-\mathrm{C}_{4}\right)^{19,28-30}$. Anaerobic hydrocarbon oxidizers that metabolize medium- to long-chain $n$-alkanes, cycloalkanes or aromatic hydrocarbons have been enriched by growing them in media containing each of these substrates ${ }^{31}$. Even though in many cases successful enrichment led to isolation of hydrocarbon-degrading strains, substantial strides in understanding the diversity, phylogeny, physiology and biochemistry of hydrocarbon degraders had already been achieved using mixed cultures $22,32-34$.

Although numerous anaerobic hydrocarbon oxidizers have been isolated ${ }^{31}$, anaerobic oxidizers of short-chain $\left(C_{1}-C_{4}\right)$ hydrocarbons grow particularly slowly, and to date, only one representative has been isolated, Desulfosarcina sp. strain BuS5 (ref. 30). Moreover, all archaeal short-chain alkane oxidizers known to date are strictly dependent on metabolic interactions with bacteria $5,18,19,27$. Consequently, unraveling the basis of archaeal hydrocarbon metabolism largely depends on establishing and studying enrichment cultures of these organisms.

Here, we describe a protocol for establishing cultures from anoxic marine sediment samples that are enriched in consortia performing anaerobic hydrocarbon-degradation coupled to sulfate reduction (i.e., hydrocarbon-oxidizing archaea and sulfatereducing bacteria) at elevated temperatures. We have primarily used this protocol to enrich thermophilic organisms because they grow faster than their low-temperature-adapted analogs. Furthermore, cultivation of short-chain hydrocarbon degraders at low temperatures led to the enrichment of free-living hydrocarbon-degrading bacteria ${ }^{35}$, which were not the within the scope of our research. However, our protocol would be also suitable for cultivating these organisms. We successfully used our approach to enrich for anaerobic methane-oxidizing communities thriving under meso- and thermophilic conditions. The resulting cultures were dominated by anaerobic methanotrophic archaea (ANME-1 clade) and Seep-SRB2 (mesophilic conditions) or ANME-1 and Ca. Desulfofervidus auxilii (HotSeep-1 clade) (thermophilic conditions) 36,37 , and thermophilic butane-oxidizing consortia consisting of $\mathrm{Ca}$. Syntrophoarchaeum (GoM-Arch87 clade) and $\mathrm{Ca}$. Desulfofervidus auxilii ${ }^{19}$. In principle, this protocol can be used to establish enrichment cultures not only with gaseous alkanes, but with any other model hydrocarbon (e.g., medium- and long-chain linear or branched alkanes, cycloalkanes, mono- or polycyclic aromatic hydrocarbons, alkylaromatic hydrocarbons), hydrocarbon mixtures, crude oil or refined products of crude oil (e.g., gasoline, kerosene). Specific considerations regarding the addition of different hydrocarbons or hydrocarbon mixtures are discussed. Moreover, by modification of only the medium composition, this protocol can be adapted to enrich for organisms that couple degradation of long-chain hydrocarbons to methane formation ${ }^{21,38}$.

Our protocol describes (i) the preparation of growth medium, (ii) the dilution of sediment samples, (iii) the maintenance of enrichment cultures, including addition of hydrocarbon substrates, incubation and activity monitoring, (iv) the propagation of enrichment cultures through regular transfer or dilution and (v) the collection and preservation of subsamples for subsequent molecular analysis including FISH analysis, DNA/RNA sequencing and metabolite analysis. The details for the molecular approaches are beyond the scope of this article. However, some recommendations for further analysis are included. On the basis of our experience, highly enriched hydrocarbon-degrading enrichment cultures are obtained in a several-months to $>1$-year effort, depending on the substrate, initial abundance of hydrocarbon degraders in the environmental sample and selection of a suitable incubation temperature. Once established, the enrichment cultures allow assessment of the identity and physiology of hydrocarbon-degrading microorganisms, circumventing their isolation.

\section{Selection of sediment samples as inoculate}

The successful enrichment of slow-growing marine anaerobic hydrocarbon degraders from environmental samples in reasonable time frames requires careful selection of the source material. To date, all successful enrichment of sulfate-dependent methane and short-chain hydrocarbon degraders used source material from sites that have a long history of hydrocarbon exposure, are actively percolated by natural gas or crude oil (e.g., sediments around hydrocarbon seepage) and show elevated concentrations of sulfide as well as inorganic carbon (i.e., the products of sulfatedependent hydrocarbon oxidation) $)^{19,30,35,39,40}$.

For the cultivation of thermophilic hydrocarbon oxidizers, naturally heated gas- and oil-rich sediments are recommended. These prerequisites are best fulfilled by hydrothermal vents in proximity to land and rivers that cause high sedimentation rates. We established our thermophilic hydrocarbon-degrading enrichment cultures from sediments of the Guaymas Basin in the Gulf of California. In the Guaymas Basin subsurface, magma intrusions heat the surrounding sediments, causing the thermogenic decay of organic matter into simple hydrocarbons and the convection-driven venting of gas- and oil-rich fluids toward the water column ${ }^{41}$. We selected sites with steep vertical temperature gradients (i.e., from 4 to $60^{\circ} \mathrm{C}$ in the uppermost $20 \mathrm{~cm}$ ) and that were highly sulfidic and rich in a complex mixture of gaseous and liquid hydrocarbons ${ }^{42}$. Other hydrothermal vents with substantial hydrocarbon seepage and at least partial sediment coverage have been described: the Juan de Fuca Ridge (i.e., Middle Valley Chowder Hill; $48^{\circ} 27.44^{\prime} \mathrm{N}, 128^{\circ} 42.51^{\prime} \mathrm{W}^{43}$ ), Northern Mid-Atlantic Ridge (i.e., Grimsey hydrothermal field; $\left.66^{\circ} 35.50^{\prime} \mathrm{N}, 17^{\circ} 39.30^{\prime} \mathrm{W}^{44}\right)$ and Loki's Castle $\left(73^{\circ} 30^{\prime} \mathrm{N}, 8^{\circ} 09^{\prime} \mathrm{E}\right.$ (ref. 45)). At all these sites, widespread mats of sulfide-oxidizing bacteria indicate sulfide flux from below, caused by intense hydrocarbon-dependent sulfate reduction. An updated list of vents is provided on the InterRidge Vents Database (https:// vents-data.interridge.org/). 
For the cultivation of meso- and psychrophilic hydrocarbon oxidizers, sediments from cold seeps and mud volcanoes proved suitable. These seafloor structures are abundant at the continental shelf and margins. Compilations of global and regional seeps and vents are found elsewhere 16,46 . We performed successful enrichment from different sites ${ }^{37}$ such as cold seeps at Hydrate Ridge, Cascadia Margin, Oregon ${ }^{47}$, Mediterranean mud volcanoes and sites rich in short-chain hydrocarbons, such as the seep sites in the Northern and Southern Gulf of Mexico. Above several of the North Sea gas fields and at seeps off the Mediterranean island of Elba, anaerobic methanotrophy appears in coastal sands ${ }^{48,49}$. Here, and potentially in other sandy seeps, sediment-depleted highly active microbial cell material could be obtained by gravimetrical separation from the coarse sediment matrix ${ }^{49}$. Other sample sources may include crude oil and formation water from low-temperature oil reservoirs, contaminated anoxic aquifers, wastewater plants and soils.

Incubation conditions and expected microbial composition of produced enrichment cultures. The protocol presented here has been successfully used to enrich archaeal-bacterial consortia or single bacteria that couple the anaerobic oxidation of methane or specific short-chain hydrocarbons to the reduction of sulfate in a temperature range between 12 and $60{ }^{\circ} \mathrm{C}^{5,37,39,50}$. Generally, to enrich for environmentally relevant clades, an incubation temperature should be chosen that is close to the in situ temperature at the sampling site. Our enrichment cultures initiated with material from cold seep environments (in situ temperatures $4-12{ }^{\circ} \mathrm{C}$ ) were successful when incubated at temperatures between 12 and $20^{\circ} \mathrm{C}$, whereas those initiated with material from hydrothermally heated environments with steep temperature gradients developed hydrocarbon-dependent sulfate reduction at elevated temperatures between 37 and $60^{\circ} \mathrm{C}$. As our sediment samples were taken from marine environments, the growth medium used in the enrichment procedure was based on synthetic seawater with marine salinity and a $\mathrm{pH}$ adjusted to 7.1. For this sample type, the medium should be carbonate-buffered and supplemented with phosphate, ammonium and essential vitamins and trace metals according to ref. 31 . A single hydrocarbon compound should be added as an energy source, and sulfate serves as the sole provided electron acceptor. Enrichment cultures that grow under these selective conditions experience a successive decline in community complexity. This process is dynamic, and relatively stable communities are achieved after several cycles of dilution in fresh medium. Throughout the enrichment process, the development of the microbial community is monitored using $16 \mathrm{~S}$ rRNA gene amplicon sequencing or metagenomics. Further, FISH is applied to enumerate clades of interest and to discover spatial associations such as cell aggregates. The microbial composition of successful enrichment cultures predominantly depends on the source material, the supplied substrate and the incubation temperature. For instance, the enrichment of anaerobic methane oxidizers under sulfate-reducing conditions at meso- and thermophilic temperatures yielded communities dominated by ANME-1 archaea and sulfate-reducing bacteria of the Seep-SRB2 $\left(37^{\circ} \mathrm{C}\right)$ or $\mathrm{Ca}$. Desulfofervidus auxilii $\left(50-60^{\circ} \mathrm{C}\right)$ clade $36,37,50$. By contrast, the anaerobic methane-oxidizing enrichment cultures obtained at lower temperatures $\left(12^{\circ} \mathrm{C}\right.$ to room temperature $\left(20-25^{\circ} \mathrm{C}\right)$ ) were repeatedly dominated by ANME-2 archaea and sulfate-reducing bacteria of the Seep-SRB2 or
Seep-SRB1 clades, whereas the originally present ANME-1 were not enriched at low temperatures $37,39,51-53$.

Thermophilic enrichments with butane selected for the novel archaeal hydrocarbon degrader $\mathrm{Ca}$. Syntrophoarchaeum, which, like ANME, forms consortia with the sulfate reducer $\mathrm{Ca}$. Desulfofervidus auxiliii ${ }^{19}$. The in vitro enrichment of archaeal short-chain hydrocarbon degraders at lower temperatures has not been successful yet, although 16S rRNA gene sequences closely related to $\mathrm{Ca}$. Syntrophoarchaeum have been retrieved from cold seep sediments ${ }^{54}$. Instead, using the short-chain hydrocarbons propane or butane as substrate and moderate incubation temperatures, different hydrocarbon-degrading sulfate-reducing bacteria related to Desulfosarcina sp. were enriched $28,30,35$.

Although only single substrates are supplied, the enrichment cultures still contain considerable side communities: relative sequence abundance data from clone libraries, metagenomes and metatranscriptomes indicate that the hydrocarbon-degrading archaea and their partner bacteria account for $\sim 60-90 \%$ of the established enrichments ${ }^{19,37,50}$. The side communities include bacteria affiliated with Spirochaetes, Chloroflexi (Anaerolineaceae) and several other clades without cultivated representatives (Candidate divisions OP3 and KB1), and archaea affiliated with Thermoplasmata ${ }^{19,37,50}$. These organisms may thrive on cell exudates or organic compounds released from lysed cells. Other side microorganisms are even lower in abundance, but they may quickly increase in number when non-hydrocarbon substrates are provided. For instance, mesophilic anaerobic methane-oxidizing enrichment cultures contain methylotrophic methanogens (i.e., Methermicoccus spp., Methanococcoides spp. and Methanohalophilus spp.) that likely thrive on methylated compounds released by the ANME archaea during methane oxidation ${ }^{37}$. Furthermore, in these enrichment cultures, sulfurdisproportionating bacteria (e.g., GB-DISP1; Desulfocapsarelated strains ${ }^{37}$ ) may thrive on minor amounts of zero-valent sulfur likely produced during medium preparation or medium exchange. Hence, side communities must be considered when conducting and interpreting physiological experiments, as well as in all downstream molecular analyses.

Scope and extended applications of the protocol. In its presented form, this protocol has been successfully applied to enrich for methane and short-chain hydrocarbon-oxidizing microorganisms in batch cultures. With minor adjustments, this protocol can also be used to enrich for marine degraders of higher hydrocarbons, including medium- and long-chain alkanes, and aromatic or polycyclic hydrocarbons (PAHs). In such cases, different aspects must be considered. Liquid hydrocarbons with relatively high water solubility (e.g., $n$-hexane, benzene) could have a pronounced toxic effect ${ }^{55}$. We recommend adding such compounds dissolved in the inert carrier phase 2,2,4,4,6,8,8-heptamethylnonane as described before ${ }^{31}$. By contrast, long-chain alkanes (e.g., $n$-hexadecane and higher alkanes) or PAHs (e.g., phenanthrene) with very low water solubility should be added directly to the culture media as liquid or crystals. A carrier phase should be avoided for this type of hydrocarbons, as it may lead to low substrate availability in the water phase, limiting the growth rates of microorganisms (for specific solubilities, see ref. 56). Further details regarding cultivation with liquid or solid hydrocarbons are found elsewhere ${ }^{31}$. In general, care must be taken to avoid contact between 
the rubber stoppers and the organic phase, which will eventually lead to swelling and dissolution of the stoppers. We recommend incubating the bottles upside down, with the stoppers below the medium-organic phase interface. The use of Teflon-based valve systems (i.e., Mininert, from Sigma-Aldrich) has been established as an alternative to this method. As these valves are not fully gastight, experiments using these systems should be performed in anoxic chambers ${ }^{57}$. Other applications of the protocol described here include enrichment and cultivation of anaerobic microorganisms with soluble substrates (e.g., organic acids, alcohols). The preparation of stock solutions and the procedures for the addition of soluble substrates can be found elsewhere ${ }^{58}$.

In addition, the current protocol can be adapted to enrich microorganisms from freshwater or brackish habitats by adjusting the salinity of the medium according to the environmental parameters. Furthermore, as organisms from such environments often show a limited tolerance to sulfide, the medium should be exchanged at low sulfide concentrations (e.g., $5 \mathrm{mM}$ ). For details and further considerations regarding freshwater medium compositions, see refs. 31,58.

In addition, if sulfate is omitted from the medium (i.e., magnesium sulfate replaced by an equimolar amount of magnesium chloride), the protocol can be used to enrich and cultivate methanogenic archaea. As methanogenic microbial communities are highly sensitive to free sulfide or dithionite, amorphous ferrous iron has been successfully applied as an alternative reductant in the medium ${ }^{57,59}$. Metabolic activity in methanogenic enrichment cultures is usually monitored by using gas chromatography to track the development of methane concentrations ${ }^{38}$.

Alternative approaches for enriching marine anaerobic methane-oxidizing consortia include the utilization of pressurized vessels ${ }^{60}$ and the use of flow-through systems operated at ambient ${ }^{61}$ or high pressures ${ }^{51-53,62,63}$. Most of these studies used media with similar compositions to the one described here. However, the use of these highly expensive and laborious techniques did not substantially increase the biomass yields or growth rates of these microorganisms. Hence, these techniques instead suit specific applications, such as to yield in situ pressures or to simulate temperature gradients ${ }^{64}$.

\section{Experimental design}

Here we describe the step-by-step procedure for the substratespecific enrichment of hydrocarbon-degrading microorganisms and the retrieval of enrichment subsamples to monitor cultivation progress. Although we focus on describing the establishment of methane- and short-chain hydrocarbon-degrading enrichment cultures, we note the minor modifications necessary to adapt this protocol for the enrichment of degraders of other hydrocarbons (see above). The protocol is suitable for the production of initially ten replicate enrichment cultures $(100 \mathrm{ml})$ from $\sim 100 \mathrm{ml}$ of wet surface sediment suspended in 1,000 ml of medium. This sediment density proved optimal for establishing a vigorous hydrocarbon-degrading community from our sediment samples (i.e., Guaymas Basin sediments; see above). In practical terms, this setup leaves sufficient clear medium for chemical measurements once sediment particles have settled. This protocol describes the procedure for cultivation in 156-ml bottles with $100 \mathrm{ml}$ of culture. The remaining $56-\mathrm{ml}$ headspace allows for the provision of the gaseous hydrocarbon substrate in excess $(2 \mathrm{mmol}$ at $100 \mathrm{kPa})$. This setup is easily adaptable to other culture volumes. Care should be taken to keep a headspace-to-medium ratio of not $<1: 2$ to ensure the supply of sufficient amounts of gaseous substrates, and larger bottles should be constantly slowly agitated to avoid diffusion limitation. To test for activity on endogenous substrates, replicate enrichment cultures without hydrocarbon addition (i.e., sediment slurry only) should be prepared and maintained. The regular measurement of sulfide allows the rapid determination of the activity and, hence, monitoring of the enrichment progress. The growth medium of the enrichment cultures should be exchanged when sulfide concentrations reach $\sim 15 \mathrm{mM}$. At this stage, culture material (i.e., biomass and remaining sediment) can be diluted to achieve sediment-free enrichment cultures over time. Due to the enrichment process, cultivation may be accompanied by severe community shifts. Hence, several dilution and enrichment cycles should be performed to describe the community responsible for the turnover of a specific substrate. Our protocol also describes the necessary sampling steps to perform culture-independent methods on the produced enrichment cultures.

To reduce potential inhibitory effects by contaminants, we recommend working under sterile conditions even when setting up initial incubations for enrichment. General good microbiological practice should be followed. This includes sterile work next to a flame when critical. Once replicate enrichment cultures on different substrates are set up, cross-contaminations should be avoided by using new disposable material (e.g., needles and syringes) for each enrichment culture, whereas non-disposable material (e.g., metallic tweezers) should be sterilized.

We start with the preparation and handling of culture medium (Step 1; Fig. 1), followed by establishment of enrichment cultures of thermophilic hydrocarbon-degrading microorganisms from marine sediments (Steps 2-17; Fig. 2) and monitoring of the produced enrichment/sampling of produced cultures for downstream analysis (Steps 18-23; Figs. 2 and 3). Our protocol also provides the modifications for alternative laboratory equipment. a
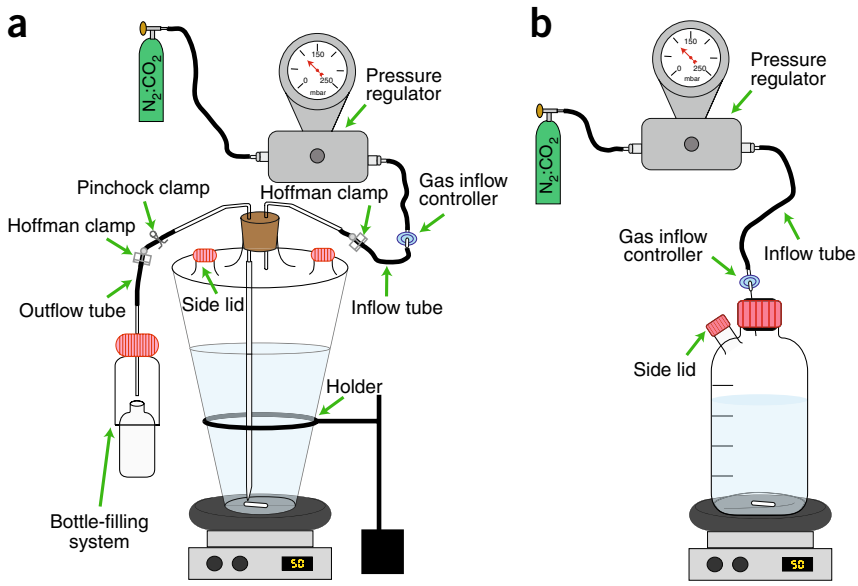

Figure 1 | Setups for the production of anaerobic medium (Step 1).

$(\mathbf{a}, \mathbf{b})$ Setups using a Widdel flask for the filling of serum vials (a) or a Duran flask manufactured with a sideward opening for medium transfers inside the anoxic chamber (b). The gas inflow controller consists of a $0.2-\mu \mathrm{m}$-pore-size filter and a Luer one-way stopcock. 


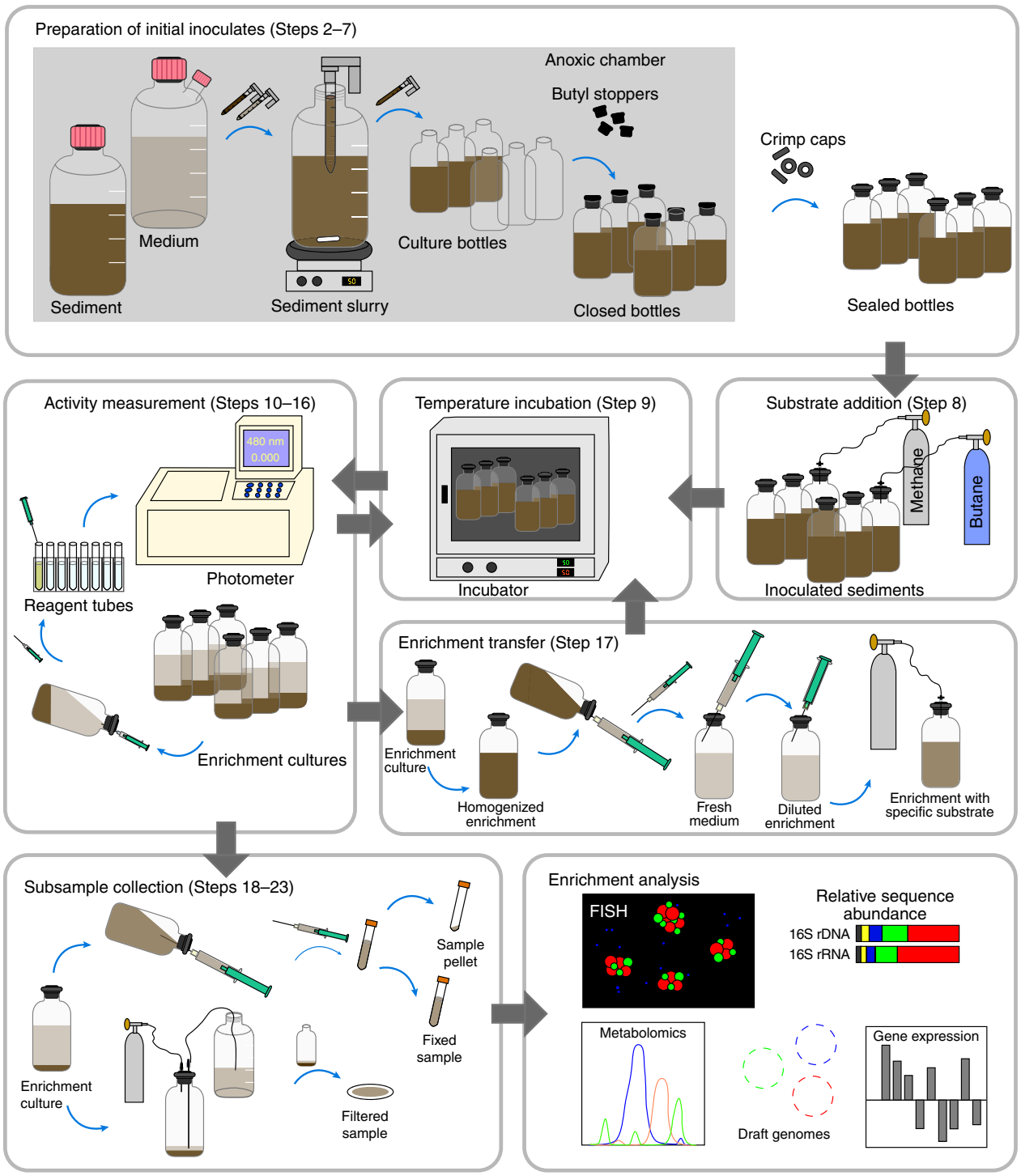

Figure 2 | Scheme illustrating the preparation of initial inoculates, the incubation and dilution of enrichment cultures, activity measurements, and subsampling for downstream analyses.

Preparation of replicate enrichment cultures from an environmental sediment sample. The preparation of the sediment sample is carried out in an anoxic chamber to prevent exposure to oxygen. The preparation of inoculates without an anoxic chamber can be achieved by working under a constant stream of anoxic gas, preferably, a $\mathrm{N}_{2}: \mathrm{CO}_{2}$ mixture. However, this approach is more difficult and involves the risk of poisoning highly sensitive organisms with oxygen. The source sediment is diluted $(\sim 1: 10)$ in anoxic medium. The resulting slurry is evenly distributed to designated serum bottles (i.e., 156-ml serum bottles) filled approximately to $2 / 3$ $(100 \mathrm{ml})$. To increase the rate of success, we recommend preparing replicate incubations for each setup (i.e., hydrocarbon substrate and temperature). To achieve even sediment content in replicates, the sediment slurry should be kept homogeneous through continuous stirring during the distribution into serum bottles. Samples for dry weight determination and molecular analyses (such as tag sequencing, FISH or metagenomic analysis) should be collected at this stage to describe the source material. Bottles are sealed with gas-tight butyl rubber stoppers and aluminum crimp caps. All bottles prepared in anoxic chambers operated with partial hydrogen atmosphere must be flushed with $\mathrm{N}_{2}: \mathrm{CO}_{2}$ (i.e., for at least $3 \mathrm{~min}$ ) to remove this potential energy source.

Addition of hydrocarbon substrates to culture bottles. The kinetics of hydrocarbon degradation largely depends on the substrate concentrations; hence, gaseous substrates are supplied with high partial pressures. Here, we used $250-\mathrm{kPa}$ methane or $100-\mathrm{kPa}$ butane.

Incubation of enrichment cultures. Enrichment cultures are incubated in temperature-controlled incubators in the dark. Substrate availability to the cells is important; however, constant shaking of samples has often shown negative effects in the cultures; we recommend that samples be agitated weekly. 


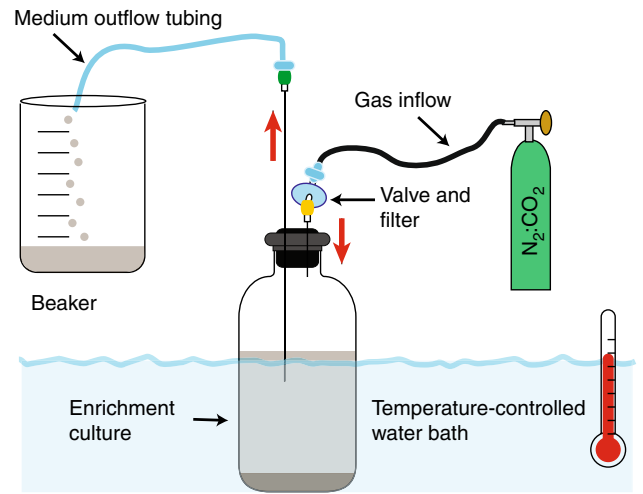

Figure 3 | Setup for the temperature-controlled fixation of cell material for transcriptome analysis (Step 23C(ii-vi)). The enrichment culture is kept at constant temperature using a heated water bath. The gas bottle is connected to the culture bottle. A long needle connected to a PVC Luer tube is injected into the culture bottle. The inflowing gas replaces the medium. After the medium is removed, RNAlater is added to preserve the RNA.

Tracking of metabolic activity in the enrichment cultures. Well-growing enrichment cultures should show exponentially increasing cell numbers or an exponential accumulation of reaction product(s) in the medium. A convenient method of tracking the metabolic activity of sulfate-reducing microorganisms is to determine sulfide concentrations using a simple photometric assay ${ }^{65,66}$. Alternatively, sulfate or hydrocarbon (i.e., methane, butane) concentrations can be determined using ion or gas chromatography, respectively.
Maintenance and dilution of the enrichment cultures. When sulfide concentrations reach inhibitory or even potentially toxic levels $(\sim 15 \mathrm{mM})$, the medium should be exchanged. At this stage, the enrichment culture is usually diluted. For instance, anaerobic methane-oxidizing enrichment cultures with a doubling time of $60 \mathrm{~d}$ and an activity causing a critical sulfide level $(15 \mathrm{mM})$ in $90 \mathrm{~d}$ should be diluted 1:2. For faster-growing enrichment cultures, such as butane-oxidizing enrichment cultures, dilutions of 1:5 are suitable. We define an enrichment culture as established once it has been successfully subjected to at least three consecutive dilution steps.

Collection and preservation of enrichment material for subsequent analysis. Once an enrichment culture has been established, it can be characterized by various molecular approaches. The collection and preservation of enrichment material differ depending on the desired analysis. Some approaches may require using a whole culture bottle, whereas others require only subsamples. We provide an overview of the material collection and preservation for a selection of subsequent analyses that we consider most important based on our experience with enrichment cultures. These include FISH, amplicon sequencing, metagenomics and transcriptomics. For metabolomic analyses, we describe the preparation of samples for highresolution mass spectrometry (MS) (i.e., Fourier transform ion cyclotron resonance MS or Orbitrap-based MS) based on direct sample infusion. This approach avoids additional processing steps (e.g., chemical derivatization), which usually demand high amounts of sample.

\section{MATERIALS}

\section{REAGENTS}

\section{Original sample}

- Here we describe the enrichment procedure for marine samples recovered after visual inspection of the sampling site. For rapid enrichment, process intact sediment material (i.e., collected by push coring with 6 - $\mathrm{cm}$-diameter cores) from defined hydrocarbon-rich, sulfidic spots. Avoid drained cores, as microbial activity might be strongly affected by inflow of oxygen. A collection of comprehensive metadata, including exact position, temperature range and, if possible, pore-water chemistry (i.e., hydrocarbon concentrations and sulfate, sulfide and inorganic carbon concentrations, from replicate samples) is important to describe the original sample. Core sections of interest for cultivation are transferred to sterile glass bottles (i.e., GL 45 glass bottles). Avoid air pockets in the sample and close the bottles with gas-tight butyl rubber stoppers. If the bottles are not completely filled with sediment, headspace should be exchanged with anoxic gas (i.e., $\mathrm{N}_{2}$, argon). Alternatively, fill the bottles completely with anoxic reduced medium prepared as described below. Samples collected to produce thermophilic enrichments can be stored at room temperature; if enrichments at lower temperatures are planned, a storage temperature of $4^{\circ} \mathrm{C}$ is recommended. In this way samples can be stored for at least two months without losing substantial microbial activity, as tested for the enrichment of meso- and thermophilic anaerobic methane-oxidizing archaea. To maximize the cultivation success, we recommend starting the cultivation procedure as soon as possible (within weeks) after sampling. However, after longer sample storage times ( $>6$ months), many organisms (in particular, those performing the anaerobic oxidation of methane) can be enriched from anoxic sediment samples. For each enrichment culture (156-ml bottle), 5-20 $\mathrm{ml}$ of the original sediment sample should be used. Enrichment attempts with higher dilutions may not be successful when targeting rare processes and organisms.

\section{Gases}

$\triangle$ CRITICAL Hydrocarbon substrates should be selected according to planned enrichments. Specifications for gas containers, gas purity and gas regulators, including their fittings, differ regionally. This protocol uses European Union (EU) specifications; for other regions, ask your local supplier for similar purities. ! CAUTION High safety standards are required for handling pressurized and flammable gases. Wear safety googles. When not being used, store gas bottles in a ventilated storage place. When handling pressurized gases, use appropriate gas pressure reducers and connectors. Do not pressurize rubber tubing with $>2$ atm overpressure. During medium preparation in large bottles, always use low-pressure line regulators $(<0.1 \mathrm{~atm})$. Do not use a sterilization flame and other flammable gases (methane, other hydrocarbon gases) at the same time.

- $\mathrm{CH}_{4}$ (i.e., $\geq 99.9995$ mol\% N55; Air Liquide, cat. no. P0716S10R2A001)

- $\mathrm{CH}_{4}: \mathrm{CO}_{2}$ (90:10; i.e., $\geq 99.9995 \%$; Air Liquide, custom order)

- $n$-Butane (i.e. $\geq 99.95$ vol.\% N35; Air Liquide, cat. no. P0645S10R0A001)

- $\mathrm{CO}_{2}$ (i.e., $\geq 99.9995 \mathrm{~mol} \%$ N55; Air Liquide, cat. no. P1725S10R0A001)

- $\mathrm{N}_{2}$ (>99.999 mol\% (Air Liquide, cat. no. P0272L50R2A001)

- $\mathrm{N}_{2}: \mathrm{CO}_{2}$ (90:10) gas mixture (i.e., $\geq 99.995 \mathrm{~mol} \% \mathrm{~N} 45$; Air Liquide, custom order)

Chemicals

- Pure water (i.e., Milli-Q grade)

- KBr (Sigma-Aldrich, cat. no. P0838)

- $\mathrm{KCl}$ (Sigma-Aldrich, cat. no. P9333)

- $\mathrm{CaCl}_{2} \cdot 2 \mathrm{H}_{2} \mathrm{O}$ (Sigma-Aldrich, cat. no. C3306)

- $\mathrm{MgCl}_{2} \cdot 6 \mathrm{H}_{2} \mathrm{O}$ (Sigma-Aldrich, cat. no. M2670)

- $\mathrm{MgSO}_{4} \cdot 7 \mathrm{H}_{2} \mathrm{O}$ (Sigma-Aldrich, cat. no. 63138)

- $\mathrm{NaCl}$ (Sigma-Aldrich, cat. no. S7653)

- $\mathrm{CuSO}_{4} \cdot 5 \mathrm{H}_{2} \mathrm{O}$ (Sigma-Aldrich, cat. no. C8027) 
- Hydrochloric acid (HCl; 36.5-38.0\% (wt/wt); Sigma-Aldrich, cat. no. H1758)

- $\mathrm{Na}_{2} \mathrm{HPO}_{4} \cdot 2 \mathrm{H}_{2} \mathrm{O}$ (Sigma-Aldrich, cat. no. S5136)

- $\mathrm{NaH}_{2} \mathrm{PO}_{4} \cdot \mathrm{H}_{2} \mathrm{O}$ (Sigma-Aldrich, cat. no. S3522)

- $\mathrm{NaOH}$ pellets (Sigma-Aldrich, cat. no. S8045)

- $\mathrm{NaHCO}_{3}$ (Sigma-Aldrich, cat. no. S5761)

- $\mathrm{Na}_{2} \mathrm{CO}_{3}$ (Sigma-Aldrich, cat. no. S7795)

- $\mathrm{NH}_{4} \mathrm{Cl}$ (Sigma-Aldirch, cat. no. A9434)

- $\mathrm{KH}_{2} \mathrm{PO}_{4}$ (Sigma-Aldrich, cat. no. P9791)

- $\mathrm{FeSO}_{4} \cdot 7 \mathrm{H}_{2} \mathrm{O}$ (Sigma-Aldrich, cat. no. F8633)

- $\mathrm{H}_{3} \mathrm{BO}_{3}$ (Sigma-Aldrich, cat. no. B6768)

- $\mathrm{MnCl}_{2} \cdot 4 \mathrm{H}_{2} \mathrm{O}$ (Sigma-Aldrich, cat. no. M5005)

- $\mathrm{CoCl}_{2} \cdot 6 \mathrm{H}_{2} \mathrm{O}$ (Sigma-Aldrich, cat. no. C8661)

- $\mathrm{NiCl}_{2} \cdot 6 \mathrm{H}_{2} \mathrm{O}$ (Sigma-Aldrich, cat. no. N6136)

- $\mathrm{CuCl}_{2} \cdot 2 \mathrm{H}_{2} \mathrm{O}$ (Sigma-Aldrich, cat. no. C3279)

- $\mathrm{ZnSO}_{4} \cdot 7 \mathrm{H}_{2} \mathrm{O}$ (Sigma-Aldrich, cat. no. Z0251)

- $\mathrm{Na}_{2} \mathrm{MoO}_{4} \cdot 2 \mathrm{H}_{2} \mathrm{O}$ (Sigma-Aldrich, cat. no. M1651)

- Folic acid (Sigma-Aldrich, cat. no. F8758)

- Lipoic acid (Sigma-Aldrich, cat. no 07039)

-4-Aminobenzoic acid (Sigma-Aldrich, cat. no. 06930)

- D(+)-Biotin (Sigma-Aldrich, cat. no. B4639)

- Nicotinic acid (Sigma-Aldrich, cat. no. N0761)

- Ca-D(+)-Pantothenate (Sigma-Aldrich, cat. no. 21210)

- Pyridoxine dihydrochloride (Sigma-Aldrich, cat. no. P9158)

- (-)-Riboflavin (Sigma-Aldrich, cat. no. R9504)

- Thiamine hydrochloride (Sigma-Aldrich, cat. no. T1270)

- Cyanocobalamin (Sigma-Aldrich, cat. no. V6629)

- $\mathrm{Na}_{2} \mathrm{SeO}_{3} \cdot 5 \mathrm{H}_{2} \mathrm{O}$ (Sigma-Aldrich, cat. no. S89771)

- $\mathrm{Na}_{2} \mathrm{WO}_{4} \cdot 2 \mathrm{H}_{2} \mathrm{O}$ (Sigma-Aldrich, cat. no. 72069)

- Resazurin sodium salt (Sigma-Aldrich, cat. no. R7017)

- Sodium sulfide nonahydrate crystals (Fisher Scientific, cat. no. S425-500)

- Hydrogen peroxide solution $\left(\mathrm{H}_{2} \mathrm{O}_{2} ; 30 \%\right.$ (wt/wt); Sigma-Aldrich,

cat. no. H1009)

- Sodium dithionite (EMD Millipore, cat. no. 106505)

- RNAlater (Sigma-Aldrich, cat. no. R0901) $\Delta$ CRITICAL Reagent: alternative

RNA fixation reagents might require different procedures).

- Diethyl pyrocarbonate (Sigma-Aldrich, cat. no. D5758)

- RNaseZAP (Sigma-Aldrich, cat. no. R2020)

- RNase-free water (Sigma-Aldrich, cat. no. 9601)

- Quick-RNA Miniprep Kit (Zymo Research, cat. no. R1050)

- Formaldehyde solution (36.5-38.0\% in water; Sigma-Aldrich, cat. no. F8775)

- Ethanol (absolute; EMD Millipore, cat. no. 100983)

- Ammonium bicarbonate (EMD Millipore, cat. no. 533005)

- Acetonitrile (EMD Millipore, cat. no. 113212)

- Methanol (EMD Millipore, cat. no. 106002)

\section{EQUIPMENT}

- Gas controllers for the different gases and connectors (Air Liquide, custom order) to tubing (Norprene laboratory tubing (1/8-inch diameter; Sigma-Aldrich, cat. no. Z279900)) and Luer male adapters (1/8-inch diameter, Cole-Parmer, cat. no. GZ-30800-24)

- Low-pressure line regulator (GasTech, model no. Omega I 1SSLFDR-2)

- Anoxic chamber operated with $\mathrm{N}_{2}: \mathrm{CO}_{2}, 90: 10$ atmosphere to keep the $\mathrm{pH}$ of the medium constant (UNIlab Pro Glove Box Workstation (MBraun) equipped with gas purifier (MBraun, model no. MB-20-G; ask supplier for best configuration)) $\Delta$ CRITICAL Transfers in anoxic chambers operated with partial $\mathrm{H}_{2}$ atmosphere require subsequent exchange of the enrichment culture's headspace with $\mathrm{N}_{2}: \mathrm{CO}_{2}, 90: 10$ to reduce the risk of enriching hydrogen-oxidizing microorganisms.

- Duran glass bottle (1 liter, GL 45 opening; Omnilab, cat. no. 5072016)

- Medium preparation bottle ('Widdel flask') with bottle-filling system (Glasgerätebau Ochs, cat. no. 110011, or custom-order from a local manufacturer)

- Duran glass bottle (1 liter, GL 45 top opening and GL 25 side opening with screw caps (produced on request by glassware manufacturer, e.g., Glasgerätebau Ochs or a local manufacturer))

- Caps for Duran laboratory bottles (GL 25, Sigma-Aldrich,

cat. no. Z232343; GL 45, Sigma-Aldrich, cat. no. Z153958)

- Serum bottles (150 ml; Glasgerätebau Ochs, cat. no. 102046; or Wheaton, cat. no. 223950)

- Butyl rubber stoppers (Glasgerätebau Ochs, cat. nos. 102049 and 102054) and aluminum crimp caps (Glasgerätebau Ochs, cat. no. 102050; or Bellco Glass, cat. no. 2048-11020)
- Capping and decapping tongs for serum bottles (Wheaton, cat. nos. W225303 and 224373)

- Tea strainer (plastic)

- All-glass syringe (Sigma-Aldrich, cat. no. Z314560)

- Graduated glass pipettes ( $5 \mathrm{ml}$, dry sterilized; Fisher Scientific, cat. no. 13-665-3K)

- Hoffman clamps (Fisher Scientific, cat. no. 05-871B)

- Pinchcock clamps (Fisher Scientific, cat. nos. 05-850A and 05-850B)

- Laboratory spoon that fits into GL 45 opening of Duran glass bottles (e.g., Sigma-Aldrich, cat. no. Z177911)

- Diverse spatulas (e.g., Sigma-Aldrich. cat. no. Z648299)

- Magnetic cylindrical and cell-preserving H-shape magnetic stirring bars (38 mm, VWR Spinbar, cat. no. 58948-150; 32 mm, VWR Circulus, cat. no. 102095-498)

- Magnetic stirrer (IKA, cat. no. 0025004601 )

- Steam autoclave (SanoClav, cat. no. 01039)

- Brown-glass flasks for vitamin solutions (Thermo Fisher, cat. no. 149-0125)

- Glass flasks with aluminum caps for trace element solutions (Glasgerätebau Ochs, cat. no. 118100)

- Dry autoclave oven to sterilize glassware and metal ( Steriliser SN series; Memmert)

- Serological plastic pipettes (sterile, individually wrapped, $10 \mathrm{ml}$; Sigma-Aldrich, cat. no. CLS4488) for use in anoxic chamber

- Pipette controller (Powerpette Pro; VWR, cat. no. 612-3870) for use with serological pipettes

- Pipettes (Finnpipette F1, $10 \mathrm{ml}, 1 \mathrm{ml}, 200 \mu \mathrm{l}$; Thermo Fisher, cat. nos. $4641120 \mathrm{~N} ; 4641100 \mathrm{~N}$ and $4641080 \mathrm{~N}$ ) with fitting tips - Centrifuge tubes ( $2 \mathrm{ml}, 15 \mathrm{ml}, 50 \mathrm{ml}$; Sarstedt, cat. nos. 72.694.406, $62.554 .002,62.547 .004)$ for subsample collection (e.g., for dry weight determination and DNA or FISH analysis)

- Centrifuges for 50- and 15-ml tubes (Eppendorf, model no. 5810R) and for 2-ml tubes (Eppendorf, model no. 5427R)

- Sensitive laboratory balance (sensitivity 1 mg; Sigma-Aldrich, cat. no. Z662941)

- Medical syringes ( $1 \mathrm{ml}$, Injekt F-SOLO, B. Braun, cat. no. 9166017V; 5 ml,

B. Braun, cat. no. 4616057V; 50 ml, Omnifix Solo, B. Braun, cat. no. 4616502F)

- Single-use needles (Sterican single-use needles, 23-gauge $\times 1$ 1/4-inch, B. Braun, cat. no. 4657640; 20-gauge $\times 1$ 1/2-inch, B. Braun, cat. no. 4657519; 21-gauge $\times 4$ 3/4-inch, B. Braun, cat. no. 4665643; 26-gauge $\times 1$-inch, B. Braun, cat. no. 4657683)

- Photometer (UV-visible spectrophotometer; Shimadzu, cat. no. UV-1280) (The photometer is calibrated as described in Box 1.)

- Test tubes (glass) with holding volumes of 5-10 $\mathrm{ml}$ (for copper sulfate assay and $\mathrm{pH}$ measurements; Sigma-Aldrich, cat. no. Z653500)

- Single-use cuvettes ( $2.5 \mathrm{ml}$; Sigma-Aldrich, cat. no. Z330388)

- Sterile membrane syringe filters with male Luer lock outlet (Sartorius, cat. no. 16532)

- Sterile surgical disposable scalpels (B. Braun, cat. no. BA825SU)

- Disposable cell scraper (Sarstedt, cat. no. 83.1832)

- Graduated cylinders for volumes of $100 \mathrm{ml}$ and 1,000 ml (Sigma-Aldrich, cat. nos. Z131040 and Z131121)

- Volumetric flask with plastic lid for volumes of 1,000 ml (Sigma-Aldrich, cat. no. Z740783)

- Parafilm M (Sigma-Aldrich, cat. no. P7793)

- Aluminum foil (Sigma-Aldrich, cat. no. Z185140)

- Bunsen burner (Sigma-Aldrich, cat. no. Z270288)

- Incubator (Memmert, cat. no. IN750)

- pH-electrode setup (SevenCompact pH Meter with InLab Routine

(Mettler Toledo) and Go-SIM pH electrode (Mettler Toledo))

- Bead-beating machine (MP Biomedicals, cat. no. 116004500)

- Lysing Matrix E (2-ml tube; MP Biomedicals, cat. no. 116914100)

- Heating bath (ICC basic; IKA)

- Sterile PVC male Luer-Lock tubing (Cole-Parmer, cat. no. GZ-30600-62)

- Stopcock with Luer connections (one-way; Cole Parmer, cat. no. GZ-30600-00)

- Stopcock with Luer connections (three-way; Cole Parmer,

cat. no. GZ-30600-02)

- Tweezers (sterilized; Sigma-Aldrich, cat. no. F4517)

-500-ml Beaker (Sigma-Aldrich, cat. no. BR87616)

- Membrane filter (Whatman Nuclepore Track-Etched Membrane,

diameter $=47 \mathrm{~mm}$, pore size $=0.2 \mu \mathrm{m}$; Sigma-Aldrich, cat. no. 111106-47)

- Cellulose nitrate membrane filter $($ diameter $=47 \mathrm{~mm}$, pore size $=0.45 \mu \mathrm{m}$; Sartorius, cat. no. 11306-47;) 


\section{Box 1 | Photometer calibration for sulfide measurements TIMING 30-60 min}

1. Pour $4 \mathrm{ml}$ of copper sulfate solution into a test tube. Prepare as many test tubes as standards to be measured plus two test tubes for blank measurements.

2. Turn the photometer on and adjust the wavelength settings to $480 \mathrm{~nm}$.

3. Make a blank measurement by filling a $2.5-\mathrm{ml}$ cuvette with the copper sulfate reagent and placing it in the light beam of the photometer. Set as zero value.

4. With an $\mathrm{N}_{2}$-flushed 1-ml syringe plus needle (26-gauge $\times 1$-inch), sample $\sim 0.3 \mathrm{ml}$ of an anoxic sulfide standard and inject exactly $0.1 \mathrm{ml}$ of the standard into the test tube filled with copper sulfate solution. A brown copper sulfide precipitate should form immediately. Quickly seal the test tube (e.g., with a piece of Parafilm), gently mix by inverting the tube two to three times and carefully pour the entire contents into a $2.5-\mathrm{ml}$ cuvette, which holds up to $4 \mathrm{ml}$. Immediately measure the absorption by placing the cuvette in the light beam of the photometer.

5. Proceed with the next standard. Use a new syringe and needle for each standard.

6. Prepare a calibration curve (concentration versus measured absorption) and use it to determine the sulfide concentration.

- Nalgene polysulfone reusable bottle-top filter (Thermo Fisher,

cat. no. DS0320-5045)

- Glass Petri dishes, sterilized (Sigma-Aldrich, cat. no. CLS70165101)

- Light microscope (Axio Scope A1; Zeiss, cat. no. 490035-0002-000) with standard oculars

- Microscope slides (Sigma-Aldrich, cat. no. S8400)

- Cover glasses (Sigma-Aldrich, cat. no. C9056-1CS)

- Benchtop bead-based homogenizer (Mo Bio Laboratories, model no. PowerLyzer 24)

- Glass beads (0.1-mm diameter, sterilized; Roth, cat. no. N029.1)

- 2-ml Glass vials (Zinsser NA, cat. no. 3088102) with Teflon-lined screw caps (Zinsser NA, cat. no. 3088933)

\section{REAGENT SETUP}

PBS $(1 \times$ PBS/10 $\times$ PBS; $p H$ 7.4) Prepare $1 \times$ PBS from a $10 \times$ concentrated solution ( $10 \times$ PBS; $\mathrm{pH} 7.4)$ by dilution in Milli-Q water. For 1 liter of $1 \times \mathrm{PBS}$, add to a 1-liter volumetric flask $100 \mathrm{ml}$ of $10 \times$ PBS and $900 \mathrm{ml}$ of Milli-Q water. Always filter-sterilize $1 \times$ PBS aliquots before use. To prepare $10 \times$ PBS, add to a graduated cylinder $80 \mathrm{~g}$ of NaCl, $2 \mathrm{~g}$ of $\mathrm{KCl}, 26.8 \mathrm{~g}$ of $\mathrm{Na}_{2} \mathrm{HPO}_{4} \cdot 7 \mathrm{H}_{2} \mathrm{O}, 2.4 \mathrm{~g}$ of $\mathrm{KH}_{2} \mathrm{PO}_{4}$ and fill up to $800 \mathrm{ml}$ with Milli-Q water. Adjust the $\mathrm{pH}$ to 7.4 with $\mathrm{NaOH}$ solution $(1 \mathrm{M})$ or $\mathrm{HCl}$ and fill up to $1,000 \mathrm{ml}$ with Milli-Q water. Transfer the solution to a 1-liter volumetric flask and autoclave $\left(121^{\circ} \mathrm{C}, 25 \mathrm{~min}\right)$ it. This solution can be stored at room temperature for years.

$\mathrm{HCl}$ solution (1 M/0.1 M) Prepare a $1 \mathrm{M} \mathrm{HCl}$ solution in a glass flask by adding $20 \mathrm{ml}$ of $37 \%$ (12 M) HCl to $220 \mathrm{ml}$ of Milli-Q water. Prepare a $0.1 \mathrm{M}$ $\mathrm{HCl}$ solution by diluting $10 \mathrm{ml}$ of $1 \mathrm{M} \mathrm{HCl}$ in $90 \mathrm{ml}$ of Milli-Q water. Filtersterilize before use. A filter-sterilized solution stored at room temperature can be used for several years. ! CAUTION Always add the acid to the water in order to prevent vigorous exothermic reactions.

$\mathrm{NaOH}$ solution $(\mathbf{M})$ Prepare a $1 \mathrm{M} \mathrm{NaOH}$ solution in a glass flask by adding $40 \mathrm{~g}$ of $\mathrm{NaOH}$ pellets to 1 liter of Milli-Q water while mixing on a magnetic stirrer. Filter-sterilize before use. This solution can be stored at room temperature for years. ! CAUTION Add the $\mathrm{NaOH}$ slowly, as its dissolution in water releases considerable heat.

Sodium carbonate $\left(\mathrm{Na}_{2} \mathrm{CO}_{3}\right)$ solution $(1 \mathrm{M})$ To a volumetric flask, add $800 \mathrm{ml}$ of Milli-Q water and a magnetic stirring bar. While mixing on a magnetic stirrer, add $142.019 \mathrm{~g}$ of $\mathrm{Na}_{2} \mathrm{CO}_{3}$. Close the volumetric flask with the lid and stir until salts are dissolved. Fill up with Milli-Q water to 1,000 ml. Transfer $100-\mathrm{ml}$ aliquots to serum bottles $(156 \mathrm{ml})$. Close the serum bottles with butyl rubber stoppers plus aluminum crimp caps and exchange the headspace with $\mathrm{CO}_{2}$ gas. Autoclave the serum bottles for $20 \mathrm{~min}$ at $121^{\circ} \mathrm{C}$ and store them at room temperature. Solutions last at least 6 months. Discard if carbonates precipitate.

Ammonium phosphate $\left(\mathrm{NH}_{4} \mathrm{Cl}+\mathrm{KH}_{2} \mathrm{PO}_{4}\right)$ solution To a graduated cylinder, add $900 \mathrm{ml}$ of Milli-Q water and a magnetic stirring bar. While mixing on a magnetic stirrer, add $15.71 \mathrm{~g}$ of $\mathrm{NH}_{4} \mathrm{Cl}$ and $8.00 \mathrm{~g}$ of $\mathrm{KH}_{2} \mathrm{PO}_{4}$. Fill up with Milli-Q water to $1,000 \mathrm{ml}$ and stir until salts are dissolved. Transfer $25-\mathrm{ml}$ aliquots to serum bottles $(100 \mathrm{ml})$, close the serum bottles with butyl rubber stoppers plus aluminum crimp caps and flush with $\mathrm{N}_{2}$ gas (gentle gas stream, $\sim 5 \mathrm{~min}$ ). Autoclave for $20 \mathrm{~min}$ at $121^{\circ} \mathrm{C}$. Solutions stored at room temperature last for at least 1 year.
Sodium bicarbonate $\left(\mathrm{NaHCO}_{3}\right)$ solution $(1 \mathrm{M})$ To a volumetric flask, add $800 \mathrm{ml}$ of Milli-Q water and a magnetic stirring bar. While mixing on a magnetic stirrer, add $84.01 \mathrm{~g}$ of $\mathrm{NaHCO}_{3}$. Close the volumetric flask with the lid and stir until salts are dissolved. Fill up with Milli-Q water to 1,000 ml. Transfer $30-\mathrm{ml}$ aliquots to serum bottles $(100 \mathrm{ml})$. Close the serum bottles with butyl rubber stoppers plus aluminum crimp caps and exchange headspace with $\mathrm{CO}_{2}$ by purging for $5 \mathrm{~min}$. Add a $\mathrm{CO}_{2}$ headspace to $130 \mathrm{kPa}$. Autoclave the serum bottles in a dedicated rack for $20 \mathrm{~min}$ at $121^{\circ} \mathrm{C}$ and store them at room temperature. Solutions last at least 6 months. Discard if carbonates precipitate.

Non-chelated trace element mixture The non-chelated trace element mixture is prepared according to ref. 31 . To a graduated cylinder, add $50 \mathrm{ml}$ of Milli-Q water and a magnetic stirring bar. While mixing on a magnetic stirrer, add $2.1 \mathrm{~g}$ ( $7.5 \mathrm{mmol}) \mathrm{FeSO}_{4} \cdot 7 \mathrm{H}_{2} \mathrm{O}$ and $8.8 \mathrm{ml}$ of fuming $\mathrm{HCl}(37 \%)$. Allow mixing by slight stirring for a few minutes before adding $900 \mathrm{ml}$ of Milli-Q water, $60 \mathrm{mg}$ of $\mathrm{H}_{3} \mathrm{BO}_{3}, 1 \mathrm{~g}$ of $\mathrm{MnCl}_{2} \cdot 4 \mathrm{H}_{2} \mathrm{O}, 380 \mathrm{mg}$ of $\mathrm{CoCl}_{2}$. $6 \mathrm{H}_{2} \mathrm{O}, 240 \mathrm{mg}$ of $\mathrm{NiCl}_{2} \cdot 6 \mathrm{H}_{2} \mathrm{O}, 2 \mathrm{mg}$ of $\mathrm{CuCl}_{2} \cdot 2 \mathrm{H}_{2} \mathrm{O}, 288 \mathrm{mg}$ of $\mathrm{ZnSO}_{4}$. $7 \mathrm{H}_{2} \mathrm{O}$ and $72 \mathrm{mg}$ of $\mathrm{Na}_{2} \mathrm{MoO}_{4} \cdot 2 \mathrm{H}_{2} \mathrm{O}$. Fill up with Milli-Q water to $1,000 \mathrm{ml}$ and keep stirring until salts are dissolved. Transfer 50-ml aliquots to glass flasks and close with aluminum screw caps. Autoclave solutions at $121^{\circ} \mathrm{C}$ for $20 \mathrm{~min}$, allow cooling to room temperature and store them at $4{ }^{\circ} \mathrm{C}$. If refrigerated, solution can be used for at least 1 year.

Vitamin mixture The vitamin mixture is prepared according to ref. 31 . Prepare two autoclaved $\left(20 \mathrm{~min}, 121^{\circ} \mathrm{C}\right)$ brown-glass flasks $(\sim 50 \mathrm{ml})$ and aluminum screw caps. To a graduated cylinder, add $100 \mathrm{ml}$ of a $\mathrm{NaH}_{2} \mathrm{PO}_{4}$ $\mathrm{H}_{2} \mathrm{O}$ solution (10 mM, pH 7.1) and a magnetic stirring bar. While mixing on a magnetic stirrer, add $4 \mathrm{mg}$ of 4 -aminobenzoic acid, $1 \mathrm{mg}$ of $\mathrm{D}(+)$-Biotin, $10 \mathrm{mg}$ of nicotinic acid, $5 \mathrm{mg}$ of $\mathrm{Ca}-\mathrm{D}(+)$-pantothenate, $15 \mathrm{mg}$ of pyridoxine dihydrochloride, $4 \mathrm{mg}$ of folic acid and $1.5 \mathrm{mg}$ of lipoic acid. Keep stirring until the salts are dissolved. Transfer 50-ml aliquots to the autoclaved glass flasks by filter-sterilizing the solution through a $0.2-\mu \mathrm{m}$-pore-size syringedriven filter. Close flasks with autoclaved aluminum screw caps and store them at $4{ }^{\circ} \mathrm{C}$. If stored refrigerated, solutions can be used for at least 1 year. $\Delta$ CRITICAL Work next to flame and under sterile conditions.

Riboflavin solution Riboflavin solution is prepared according to ref. 31 . Prepare two autoclaved $\left(20 \mathrm{~min}, 121^{\circ} \mathrm{C}\right)$ brown-glass flasks $(\sim 50 \mathrm{ml})$ and aluminum screw caps. To a graduated cylinder, add $100 \mathrm{ml}$ of a $\mathrm{NaH}_{2} \mathrm{PO}_{4}$. $\mathrm{H}_{2} \mathrm{O}$ solution ( $25 \mathrm{mM}, \mathrm{pH} 3.2$ ) and a magnetic stirring bar. While mixing on a magnetic stirrer, add $2.5 \mathrm{mg}$ of riboflavin and keep stirring until it is dissolved. Transfer 50 -ml aliquots to the autoclaved glass flasks by filter-sterilizing the solution through a $0.2-\mu \mathrm{m}$-pore-size syringe-driven filter. Close flasks with autoclaved aluminum screw caps and store them at $4{ }^{\circ} \mathrm{C}$. If stored refrigerated, solutions can be used for at least 1 year. $\Delta$ CRITICAL Work next to flame and under sterile conditions.

Thiamine solution Thiamine solution is prepared according to ref. 31 . Prepare two autoclaved $\left(20 \mathrm{~min}, 121^{\circ} \mathrm{C}\right)$ brown-glass flasks $(\sim 50 \mathrm{ml})$ and aluminum screw caps. To a graduated cylinder, add $100 \mathrm{ml}$ of a $\mathrm{NaH}_{2} \mathrm{PO}_{4}$ $\mathrm{H}_{2} \mathrm{O}$ solution (25 mM, pH 3.4) and a magnetic stirring bar. While mixing on a magnetic stirrer, add $10 \mathrm{mg}$ of thiamine hydrochloride and keep stirring 
until complete dissolution. Transfer 50-ml aliquots to the autoclaved glass flasks by filter-sterilizing the solution through a $0.2-\mu \mathrm{m}$-pore-size syringedriven filter. Close flasks with autoclaved aluminum screw caps and store them at $4{ }^{\circ} \mathrm{C}$. If stored refrigerated, solutions can be used for at least 1 year. $\Delta$ CRITICAL Work next to flame and under sterile conditions.

Vitamin $B_{12}$ solution Vitamin $B_{12}$ solution is prepared according to ref. 31 . Prepare two autoclaved $\left(20 \mathrm{~min}, 121^{\circ} \mathrm{C}\right)$ brown-glass flasks ( $\left.\sim 50 \mathrm{ml}\right)$ and aluminum screw caps. To a graduated cylinder, add $100 \mathrm{ml}$ of Milli-Q water and a magnetic stirring bar. While mixing on a magnetic stirrer, add $5 \mathrm{mg}$ of cyanocobalamin and keep stirring until it is dissolved. Transfer 50-ml aliquots to the autoclaved glass flasks by filter-sterilizing the solution through a $0.2-\mu \mathrm{m}$-poresize syringe-driven filter. Close the flasks with autoclaved aluminum screw caps and store them at $4{ }^{\circ} \mathrm{C}$. If stored refrigerated, the solution can be used for at least 1 year. $\Delta$ CRITICAL Work next to flame and under sterile conditions. Selenite-tungstate solution Selenite-tungstate solution is prepared according to ref. 31. Prepare two autoclaved $\left(20 \mathrm{~min}, 121^{\circ} \mathrm{C}\right)$ glass flasks $(\sim 50 \mathrm{ml})$ and aluminum screw caps. To a graduated cylinder, add 1,000 $\mathrm{ml}$ of Milli-Q water and a magnetic stirring bar. While mixing on a magnetic stirrer, add $400 \mathrm{mg}$ of $\mathrm{NaOH}$ pellets, $6 \mathrm{mg}$ of $\mathrm{Na}_{2} \mathrm{SeO}_{3} \cdot 5 \mathrm{H}_{2} \mathrm{O}, 8 \mathrm{mg}$ of $\mathrm{Na}_{2} \mathrm{WO}_{4} \cdot 2 \mathrm{H}_{2} \mathrm{O}$ and keep stirring until the salts are dissolved. Transfer 50 -ml aliquots to the autoclaved glass flasks by filter-sterilizing the solution through a $0.2-\mu \mathrm{m}$-pore-size syringe-driven filter. Close the flasks with autoclaved aluminum screw caps and store them at $4{ }^{\circ} \mathrm{C}$. If stored refrigerated, solution can be used for at least 1 year. $\triangle$ CRITICAL Work next to flame and under sterile conditions. Resazurin solution Prepare two autoclaved $\left(20 \mathrm{~min}, 121^{\circ} \mathrm{C}\right)$ glass flasks $(\sim 50 \mathrm{ml})$ and aluminum screw caps. To a graduated cylinder, add $100 \mathrm{ml}$ of Milli-Q water and a magnetic stirring bar. While mixing on a magnetic stirrer, add $0.5 \mathrm{~g}$ of resazurin sodium salt and keep stirring until it is dissolved. Transfer $50-\mathrm{ml}$ aliquots to autoclaved serum flasks by filter-sterilizing the solution through a $0.2-\mu \mathrm{m}$-pore-size syringe-driven filter. Close the flasks with autoclaved aluminum caps and store them at $4{ }^{\circ} \mathrm{C}$. This solution can be used for at least 1 year if stored refrigerated. $\triangle$ CRITICAL Work next to flame and under sterile conditions.
Sodium sulfide $\left(\mathrm{Na}_{2} \mathrm{~S}\right)$ solution $(1 \mathrm{M})$ as medium reducing agent To a small volumetric flask, add $150 \mathrm{ml}$ of Milli-Q water and a magnetic stirring bar. While mixing on a magnetic stirrer, submerge a long needle (21-gauge $\times 43 / 4$ inches) connected to $\mathrm{N}_{2}$ gas and flush the Milli-Q water with $\mathrm{N}_{2}$ gas (gentle gas stream). Using a plastic spatula, add $14 \mathrm{~g}$ of large sodium sulfide nonahydrate crystals to a tea strainer. Rinse the $\mathrm{Na}_{2} \mathrm{~S}$ crystals with a bit of Milli-Q water to remove the oxidized top layer. Cleaned $\mathrm{Na}_{2} \mathrm{~S}$ crystals should be clear. Dry the $\mathrm{Na}_{2} \mathrm{~S}$ crystals with paper tissue and add to the $\mathrm{N}_{2}$-flushed Milli-Q water. Close the volumetric flask with a butyl rubber stopper, allowing the needle to stay submerged in the solution. Keep stirring and flushing the solution with $\mathrm{N}_{2}$ gas until the $\mathrm{Na}_{2} \mathrm{~S}$ is dissolved. Flush an empty serum bottle with $\mathrm{N}_{2}$ gas ( $\sim$ bar, $2 \mathrm{~min}$ ) to remove oxygen and fill $\sim 2 / 3$ of the serum bottle volume with $\mathrm{Na}_{2} \mathrm{~S}$ solution. Close the bottle with an autoclaved butyl rubber stopper and an aluminum crimp cap. Flush the headspace with $\mathrm{N}_{2}$ gas (gentle gas stream) for $5 \mathrm{~min}$ and autoclave the serum bottle at $121^{\circ} \mathrm{C}$ for $20 \mathrm{~min}$. This $\mathrm{Na}_{2} \mathrm{~S}$ solution can be used for at least 1 year, if stored refrigerated. ! CAUTION $\mathrm{Na}_{2} \mathrm{~S}$ solution is toxic and volatile; work in a fume hood. $\triangle$ CRITICAL Make sure that $12 \mathrm{~g}$ of $\mathrm{Na}_{2} \mathrm{~S}$ crystals is left after the washing procedure.

Sulfide standards for calibration of photometer Prepare sodium sulfide $\left(\mathrm{N}_{2} \mathrm{~S}\right)$ stock solution $(1 \mathrm{M})$ as described above. The exact concentrations of sulfide should be determined iodometrically as described before ${ }^{66-68}$. Prepare anoxic Milli-Q water by adding 1 liter of Milli-Q water to a 1-liter Duran glass bottle with a side opening. After adding a magnetic stirring bar, close the top opening (GL 45 thread) with a butyl rubber stopper plus a screw cap and close the side opening loosely with a screw cap. Steam autoclave the bottle but do not close the steam outlet valve before the autoclave reaches $95^{\circ} \mathrm{C}$. After autoclaving, purge the bottle with $\mathrm{N}_{2}$ gas as described for medium preparation (Box 2). Transfer sulfide stock solution, graduated cylinders, serum bottles, butyl rubber stoppers and anoxic water to an anoxic chamber. Prepare sulfide standards from mixtures of stock solution and anoxic water (i.e., $0-20 \mathrm{mM}$ sulfide final conc.). Add standards to serum bottles and close with butyl rubber stoppers. Remove from anoxic chamber, close with aluminum crimps and add a small $\mathrm{N}_{2}$ overpressure $(50 \mathrm{kPa})$. These solutions can be used for

\section{Box 2 | Preparation of anoxic medium TIMING 20 min}

The preparation of anoxic medium requires a constant supply of an anoxic headspace, which is achieved by a continuous $\mathrm{N}_{2}$ or $\mathrm{N}_{2}: \mathrm{CO}_{2}$ gas inflow. The setup to regulate this gas inflow differs between the Widdel flask and the Duran glass bottle with a sideward opening. Medium preparation in a Widdel flask (Step 1A)

1. Place the autoclaved Widdel flask in a holder above a magnetic stirrer (Fig. 1a).

2. Attach a Luer one-way stopcock with an attached $0.2-\mu \mathrm{m}$-pore-size syringe filter to the inflow tube (gas inflow controller).

! CAUTION Stopcock must be closed!

3. Remove the Hoffman clamp from the inflow tube.

4. During medium preparation, the Widdel flask's inflow and outflow are controlled as follows: to flush the headspace, the gas inflow controller is connected via the pressure regulator to a pressurized gas bottle (Step $1 \mathrm{~A}(\mathrm{iv})$ and Step $1 \mathrm{~A}(\mathrm{vi})$ ) and then a side lid of the Widdel flask and the stopcock are opened.

5. To maintain a headspace on the Widdel flask (Step $1 \mathrm{~A}(\mathrm{v})$ ), the gas inflow controller is connected to the pressurized gas bottle through a pressure regulator (operated at $5 \mathrm{kPa}$ ), and then the side lid is closed and the stopcock is opened.

6. To distribute the medium into serum flasks (Step $1 \mathrm{~A}(\mathrm{ix})$ ), the gas inflow controller is set up as in step 5, the outflow tube is connected to the glass pipe of the bottle-filling system, the Hoffman clamp is removed, and the pinchcock clamp is used to control the medium outflow (i.e., releasing it allows medium outflow).

Medium preparation in a Duran glass bottle (Step 1B)

1. Place the autoclaved Duran flask on a magnetic stirrer (Fig. 1b).

2. Attach a Luer one-way stopcock with an attached $0.2-\mu \mathrm{m}$-pore-size syringe filter to a needle (20-gauge $\times 1$ 1/2-inch; gas inflow controller).

! CAUTION The stopcock must be closed!

3. Introduce the needle attached to the inflow controller through the stopper of the Duran flask.

4. During medium preparation, the gas inflow to the Duran flask is controlled as follows: to flush the headspace, the gas inflow controller is connected via the pressure regulator to the pressurized gas bottle (Step 1B(iv) and Step 1B(vi)), and the side lid of the Duran flask and the stopcock are opened.

5. To maintain a headspace on the Duran flask (Step $1 \mathrm{~B}(\mathrm{v}))$ : the gas inflow controller is connected to the pressurized gas bottle through a pressure regulator (operated at $5 \mathrm{kPa}$ ), and the side lid is closed and the stopcock is opened. 
calibration for at least 3 months if stored refrigerated $\left(4^{\circ} \mathrm{C}\right)$ in the dark. Copper sulfate solution to measure sulfide concentrations To prepare an acidified copper sulfate solution ( $5 \mathrm{mM}$ ) add $800 \mathrm{ml}$ of Milli-Q water and a magnetic stirring bar to a 1-liter volumetric flask. While mixing on a magnetic stirrer, add $50 \mathrm{ml}$ of $1 \mathrm{M} \mathrm{HCl}$ and $1.248 \mathrm{~g}$ of $\mathrm{CuSO}_{4} \cdot 5 \mathrm{H}_{2} \mathrm{O}$. Fill up with Milli-Q water to $1,000 \mathrm{ml}$ and stir until the crystals dissolve. Store the solution at room temperature; the solution can be used for at least 1 year. DEPC water for RNA extraction To a 1-liter volumetric flask, add 1 liter of Milli-Q water and a stirring bar. Add $1 \mathrm{ml}$ of diethyl pyrocarbonate (DEPC) and mix thoroughly on a magnetic stirrer. Incubate this solution at $37^{\circ} \mathrm{C}$ for at least $12 \mathrm{~h}$. Autoclave the DEPC-treated water twice for $20 \mathrm{~min}$ at $121^{\circ} \mathrm{C}$ to remove any residual DEPC. Store the solution at room temperature and use within 1 month. Alternatively, RNase-free water can be purchased

(Sigma-Aldrich, cat. no. 9601).

Ammonium bicarbonate buffer solution (100 mM) To a volumetric flask, add $800 \mathrm{ml}$ of Milli-Q water and a magnetic stirring bar. While mixing on a magnetic stirrer, add $7.91 \mathrm{~g}$ of ammonium bicarbonate and let the salt dissolve. Fill up with Milli-Q water to 1,000 ml. Transfer to a 1-liter Duran bottle and autoclave for $20 \mathrm{~min}$ at $121^{\circ} \mathrm{C}$. The solution can be stored at room temperature for at least 6 months.

Anoxic medium Anoxic medium is prepared as described in Box 2.

\section{EQUIPMENT SETUP}

General advice for labware in contact with samples All glassware, stirring bars and metallic equipment should be machine-washed, rinsed with Milli- $\mathrm{Q}$ water and sterilized at $160{ }^{\circ} \mathrm{C}$ for $6 \mathrm{~h}$. New stoppers should be boiled in deionized water at least three times to remove excess of flexibilizers or other potential toxic compounds introduced during the production process. Plastic and rubber material should be autoclaved at $121^{\circ} \mathrm{C}$ for $25 \mathrm{~min}$.

Anoxic chamber The anoxic chamber should be charged with an $\mathrm{N}_{2}: \mathrm{CO}_{2}$ gas mixture, and oxygen levels should be monitored. We operate our anoxic chamber with oxygen content below 0.3 p.p.m. To prevent the introduction of oxygen, all material (i.e., samples and equipment) should be passed into the anoxic chamber through an airlock, which should be evacuated and flushed with anoxic gas (here, $\mathrm{N}_{2}: \mathrm{CO}_{2}$ ) three times. The headspace of bottles containing enrichment cultures or sediment samples should be flushed with $\mathrm{N}_{2}: \mathrm{CO}_{2}$ gas before their transfer to the anoxic chamber. This reduces the introduction of hydrocarbon substrates into the anoxic chamber and thus decreases the risk of cross-contaminating enrichment cultures with different substrates. $\Delta$ CRITICAL If the anoxic chamber is operated with low amounts of hydrogen gas (i.e., 1-5 vol.\%) as reductant, samples and enrichment cultures must be purged for 2 min with $\mathrm{N}_{2}: \mathrm{CO}_{2}$ to remove the hydrogen, which could act as alternative energy source.

\section{PROCEDURE}

\section{Preparation of anoxic medium $\bigcirc$ TIMING $4 \mathrm{~h}$ hands-on over $\mathbf{2} \mathrm{d}$}

1) Preparation of basal mineral medium. To a measuring cylinder, add $900 \mathrm{ml}$ of Milli- $Q$ water and a magnetic stirring bar. While stirring, add $0.09 \mathrm{~g}$ of $\mathrm{KBr}, 0.6 \mathrm{~g}$ of $\mathrm{KCl}, 1.47 \mathrm{~g}$ of $\mathrm{CaCl}_{2} \cdot 2 \mathrm{H}_{2} 0,5.67 \mathrm{~g}$ of $\mathrm{MgCl}_{2} \cdot 6 \mathrm{H}_{2} 0,6.8 \mathrm{~g}$ of $\mathrm{MgSO}_{4} \cdot 7 \mathrm{H}_{2} 0$ and $26.37 \mathrm{~g}$ of NaCl . When the salts have dissolved, fill up to 1,000 $\mathrm{ml}$ with Milli-Q water. The anoxic medium may be prepared in a Widdel flask (option A) or a Duran glass bottle with a GL 45 thread and an additional sideward opening (hereafter referred to as a Duran flask; option B). Prepare the medium in a Widdel flask (option A; see also Supplementary Video 1 and Fig. 1a) and distribute it, using anaerobic working technique, into sterile serum bottles (e.g., for culture transfers outside an anoxic chamber; see Step 18B). If the medium is handled in an anoxic chamber (e.g., to set up, maintain or dilute culture; see Steps 2-5 and Step 17A), prepare the medium in a Duran flask (option B; see also Fig. 1b and Supplementary Video 2). We recommend preparation of medium in a Widdel flask and performing the following transfers next to a flame when sterility is most important (i.e., isolation attempts). The preparation of medium in a Duran flask and culture transfers in the anoxic chamber are recommended for early enrichments with high sediment content and to guarantee strictly anoxic conditions even throughout the transfer.

\section{(A) Preparation of anoxic medium in a Widdel flask}

(i) Setup of the Widdel flask for autoclaving. Pour the basal mineral medium into the Widdel flask. Close the gas inflow tube with a Hoffman clamp and the outflow tube with a pinchcock clamp and a Hoffman clamp; cover tube openings with aluminum foil. Also cover the bottle-filling system with aluminum foil. Close the sideward openings with screw caps, but leave one of them loose.

(ii) Autoclave the Widdel flask and the bottle-filling system for $20 \mathrm{~min}$ at $121{ }^{\circ} \mathrm{C}$. Autoclave serum bottles and butyl rubber stoppers as well. If possible, close the autoclave valve once the autoclave has been heated to $\sim 95^{\circ} \mathrm{C}$; otherwise, increase flushing time with $\mathrm{N}_{2}$ in Step $1 \mathrm{~A}$ (iii).

(iii) Setup of the Widdel flask for headspace exchange with $N_{2}$. Remove the Widdel flask from the autoclave when the temperature is $\sim 80^{\circ} \mathrm{C}$, close the side cap and place the flask in a holder above a magnetic stirrer (Widdel flask setup is also described in Box 2 and depicted in Fig. 1a).

(iv) Remove the aluminum foil from the end of the gas inflow tube and connect it to the $\mathrm{N}_{2}$ gas source through a pressure regulator. Adjust the pressure to $\sim 5 \mathrm{kPa}$ and remove the Hoffman clamp from the gas inflow tube. ! CAUTION After autoclaving, the tubing might stick together where the clamps were attached. Make sure that the tube is permeable where the clamp was attached. Loosen one side cap of the Widdel flask and open the stopcock of the gas inflow controller. Flush the Widdel flask headspace with $\mathrm{N}_{2}$ gas $(5 \mathrm{kPa})$ for 5 min while stirring.

(v) Close all lids and allow the solution to cool to room temperature while being stirred.

(vi) Setup of Widdel flask for headspace exchange with $\mathrm{N}_{2}: \mathrm{CO}_{2}$. Loosen one side lid of the Widdel flask. Exchange the gas inflow connection to $\mathrm{N}_{2}: \mathrm{CO}_{2}(90: 10 ; \sim 5 \mathrm{kPa})$. Flush the Widdel flask for 5 min and then close the side lid.

(vii) Supplement the medium through a side opening of the Widdel flask. Take care to use sterile technique and work next to a flame when opening stock solutions and the side lid of the Widdel flask to supplement the medium. Open the sodium bicarbonate $(1 \mathrm{M})$ and ammonium phosphate stock solutions using the decapping tongs and pour or pipette $30 \mathrm{ml}$ of $\mathrm{NaHCO}_{3}$ (30 mM final concentration) and $25 \mathrm{ml}$ of ammonium phosphate stock solution $\left(4.67 \mathrm{mM} \mathrm{NH}_{4} \mathrm{Cl}\right.$ 
and $1.47 \mathrm{mM} \mathrm{KH}_{2} \mathrm{PO}_{4}$ final concentration) through the side lid into the Widdel flask. With sterile glass pipettes and a pipette controller, add from stock solutions: $1 \mathrm{ml}$ each of 7-vitamin mixture, riboflavin solution, thiamine solution, vitamin $B_{12}$ solution, selenite-tungstate solution, trace element solution and resazurin solution. Using a syringe and a short needle (23-gauge $\times 1$ 1/4-inch), add $0.5 \mathrm{ml}$ of $\mathrm{Na}_{2} \mathrm{~S}$ solution. With a sterile spatula, add a small amount $(\sim 10 \mathrm{mg})$ of sodium dithionite.

(viii) Wait for the medium to change color from blue to brownish-clear. Check the $\mathrm{pH}$ by retrieving a 3-ml medium sample through the side opening using a sterile glass pipette and pipette controller. Transfer the aliquot to a test tube and immediately measure the $\mathrm{pH}$ with a pH electrode. The $\mathrm{pH}$ should be $7.1 \pm 0.2$. If necessary, adjust the $\mathrm{pH}$ with $\mathrm{HCl}$ (1 M) or $\mathrm{Na}_{2} \mathrm{CO}_{3}(1 \mathrm{M})$.

(ix) Setup of Widdel flask for medium distribution. Close all lids and keep stirring. Remove the Hoffman clamp from the outflow tube.

$\triangle$ CRITICAL STEP After autoclaving, the tubing might stick together. Make sure that the tube is permeable where the clamp was attached.

(x) Remove the aluminum foil cover from the bottle-filling system. Position the bottle-filling system with a clamp system in proximity to the outflow tube of the Widdel flask.

(xi) Remove the aluminum foil cover from the bottle-filling system and connect it to the outflow tube of the Widdel flask.

(xii) Distribution of medium into serum bottles. Work with sterile technique and next to a flame. Flush the serum bottle with $\mathrm{N}_{2}$ gas (gentle gas stream, 2-3 min) using a cotton-filled glass syringe with a metal needle.

$\triangle$ CRITICAL STEP Flame the needle to sterilize it before inserting it into the bottle.

(xiii) Add medium from the Widdel flask to the sterile serum bottle by opening the pinchcock clamp of the outflow tube. When the desired volume is reached (e.g., at the marking on the serum vial), close the clamp and flush the serum bottle headspace with $\mathrm{N}_{2}: \mathrm{CO}_{2}$ gas $(90 / 10 ; \sim 0.5 \mathrm{~min}$, gentle gas stream) using the cotton-filled glass syringe with flame-sterilized metal needle.

(xiv) Close the serum bottle with a butyl rubber stopper and an aluminum crimp cap. Handle stoppers with flame-sterilized tweezers.

(xv) Flush for an additional 1-3 min with $\mathrm{N}_{2}: \mathrm{CO}_{2}(90: 10 ; 100 \mathrm{kPa})$ gas by introducing short needles (26-gauge $\times 1$-inch) for gas inflow and outflow through the stopper.

(xvi) Set an $\mathrm{N}_{2}: \mathrm{CO}_{2}(90: 10)$ headspace pressure $(100 \mathrm{kPa})$ by removing the outflow needle and allowing the pressure to build up before removing the inflow needle. Store the medium-filled serum bottle refrigerated $\left(4^{\circ} \mathrm{C}\right)$ in the dark. Medium can be used for at least 3 months.

? TROUBLESHOOTING

(B) Preparation of anoxic medium in a Duran flask

(i) Transfer basal mineral medium to a Duran flask with a side opening.

(ii) Close top opening of the Duran flask with a butyl rubber stopper and GL 45 open screw cap. Close the sideward opening with a screw cap, but leave the cap loose.

(iii) Autoclave the Duran flask for $20 \mathrm{~min}$ at $121^{\circ} \mathrm{C}$. To deplete the oxygen in the autoclave, close the autoclave valve once it has been heated to $\sim 95^{\circ} \mathrm{C}$; otherwise, increase flushing time with $\mathrm{N}_{2}$ to 15 min in Step $1 \mathrm{~B}$ (iv).

(iv) Remove the Duran flask from the autoclave when the temperature is $\sim 80^{\circ} \mathrm{C}$, close the side cap and place the flask on a magnetic stirrer. Inject the needle of the tubing coming from the gas inflow controller (as described in Box 2, 'Medium preparation in a Duran glass bottle' and depicted in Fig. 1b) through the stopper and connect to the $\mathrm{N}_{2}$ gas source. Adjust the pressure regulator to $\sim 5 \mathrm{kPa}$ and flush the Duran flask for 5 min while stirring.

(v) Close the side lid tightly and allow the solution to cool to room temperature while being stirred.

(vi) Loosen the side lid of the Duran flask. Switch the gas inflow connection to the $\mathrm{N}_{2}: \mathrm{CO}_{2}(90: 10 ; 5 \mathrm{kPa})$ gas source via a pressure regulator. Flush the Duran flask for 5 min and then close the lid.

(vii) Supplement the medium through the side opening of the Duran flask. Work with sterile technique and next to a flame. Add $30 \mathrm{ml}$ of $\mathrm{NaHCO}_{3}$ (30 mM final concentration) and $25 \mathrm{ml}$ of ammonium phosphate stock solution (4.67 mM $\mathrm{NH}_{4} \mathrm{Cl}$ and $1.47 \mathrm{mM} \mathrm{KH}_{2} \mathrm{PO}_{4}$ final concentrations) after opening the stock bottles and pouring the contents into the Duran flask.

(viii) With sterile glass pipettes and a pipette controller, add from stock solutions through the side opening: $1 \mathrm{ml}$ each of 7 -vitamin mixture, riboflavin solution, thiamine solution, vitamin $B_{12}$ solution, selenite-tungstate solution and trace element mixture, as well as $0.5 \mathrm{ml}$ of resazurin solution.

(ix) With a disposable syringe and a short needle (23-gauge $\times 1$ 1/4-inch), add $0.5 \mathrm{ml}$ of $\mathrm{Na}_{2} \mathrm{~S}$ solution.

(x) With a sterile spatula, add a small amount $(\sim 10 \mathrm{mg})$ of sodium dithionite.

(xi) Allow the color of the medium to change from blue/pink to brownish-clear. Check the pH by retrieving a 3-ml sample of medium through the side opening using a sterile pipette. Transfer the aliquot to a test tube and immediately measure the $\mathrm{pH}$ with a pH electrode. The $\mathrm{pH}$ should be $7.1 \pm 0.2$. If necessary, adjust the $\mathrm{pH}$ with $\mathrm{HCl}(1 \mathrm{M})$ or $\mathrm{Na}_{2} \mathrm{CO}_{3}$. $(1 \mathrm{M})$. 
(xii) Continue working in the anoxic chamber for the following steps. Refer to Step 1B(xiii-xvi) for the medium transfer into serum bottles, Steps 2-7 for preparation of replicate inoculates from an environmental sample, and Step 17A for medium exchange or dilution inside an anoxic chamber.

(xiii) Transfer the following material to the anoxic chamber: the anoxic medium in a Duran flask, sterile serum bottles (e.g., $156 \mathrm{ml}$ ), sterile butyl rubber stoppers, pipette controller and sterile plastic pipettes, sterile tweezers and some paper towels.

$\Delta$ CRITICAL STEP When transferring Duran flasks to the anoxic chamber, always ensure that the side cap is loose; if the cap is tight, it is possible that the flask will break during evacuation of the airlock.

(xiv) Transfer the desired volume from the Duran flask to sterile serum bottles using a plastic pipette and a pipette controller. Close the bottles with sterile butyl rubber stoppers. Handle the stoppers with sterile tweezers.

(xv) Once the medium is distributed, remove all the material from the anoxic chamber and seal the serum bottles with aluminum crimp caps, using a capping tool.

(xvi) Set an $\mathrm{N}_{2}: \mathrm{CO}_{2}(90: 10)$ headspace pressure (100 kPa) in the serum bottles by piercing the septum with a short needle (26-gauge $\times 1$-inch) connected to the gas source, allowing pressure to build up. If medium was prepared and/or distributed under partial hydrogen atmosphere, the vials must be purged with $\mathrm{N}_{2}: \mathrm{CO}_{2}$ for several minutes (see above). Store the medium-filled serum bottles refrigerated $\left(4^{\circ} \mathrm{C}\right)$ in the dark. Medium can be used for at least 3 months. ? TROUBLESHOOTING

Preparation of replicate inoculates from an environmental sediment sample TIMING $5 \mathrm{~h}$ for ten bottles

2| Transfer the following material to an anoxic chamber: the anoxic medium in a Duran flask, an environmental sediment sample stored in a gas-tight bottle (e.g., 1,000-ml Duran bottle), pre-weighted centrifuge tubes to collect subsamples for dry weight determination, centrifuge tubes (of $15-$ and $50-\mathrm{ml}$ volume) to collect subsamples for molecular analysis, a lab spoon, a sterile H-shaped magnetic stirring bar, a sterile empty 1,000-ml Duran bottle, sterile serum bottles (e.g., $156 \mathrm{ml}$ ), sterile butyl stoppers, pipette controller and sterile plastic pipettes, sterile tweezers and some paper towels.

$\triangle$ CRITICAL STEP When transferring Duran flasks to the anoxic chamber, always ensure that the side cap is loose; if the cap is tight, it is possible that the flask will break during evacuation of the airlock.

3| Transfer the sediment sample $(\sim 100 \mathrm{ml})$ to the empty Duran bottle and prepare a slurry by adding $\sim 600 \mathrm{ml}$ of anoxic medium.

4| Add the magnetic stir bar and homogenize the slurry by constant stirring ( 500 r.p.m.). Distribute the homogeneous slurry stepwise (i.e., $4 \times 25 \mathrm{ml}$ ) into the serum bottles. For that, use a disposable plastic pipette and pipette controller until the desired volume is reached (i.e., $100 \mathrm{ml}$ ). During this procedure, take subsamples for molecular analysis (i.e., DNA extraction, FISH analysis) and dry weight determination of the produced sediment slurry ( $T_{0}$ sampling). Using a disposable plastic pipette and pipette controller, transfer $25-50 \mathrm{ml}$ of sediment slurry for DNA analysis to a centrifuge tube and 5-10 $\mathrm{ml}$ of sediment slurry for FISH analysis. For dry weight determination, see Steps 18 and 19. Close the serum bottle tightly with a butyl rubber stopper.

5| Remove culture bottles, subsamples and all equipment from the anoxic chamber.

6| Preserve samples for molecular analysis according to Step 23A(ii) for DNA samples and Step 23B(ii) for FISH analysis. These samples are required to determine the original microbial community composition of the sample. To determine the dry weight of subsamples, continue with Steps 20 and 21.

7| Seal the culture bottles with aluminum crimp caps using the capping tongs.

? TROUBLESHOOTING

Addition of hydrocarbon substrates to culture bottles TIMING $1 \mathrm{~h}$ for ten bottles

! CAUTION Work with highly flammable, explosive gases is performed in the following steps. Follow safety instructions given above (see MATERIALS section) and do not work with open flames when working with hydrocarbon gases.

8| Set up the gas bottle with pressure regulator and tubing, and connect to a Luer one-way stopcock and a sterile $0.2-\mu \mathrm{m}$ pore-size syringe filter. $\mathrm{CH}_{4}: \mathrm{CO}_{2}$ gas mixtures can be applied in flow-through (option A). Pure hydrocarbon gases such as butane should be added on top of the $\mathrm{N}_{2}: \mathrm{CO}_{2}$ headspace (option $\mathrm{B}$ ) to avoid pH change by $\mathrm{CO}_{2}$ loss. See Supplementary Video 3.

\section{(A) Flow-through method}

(i) Attach a 26-gauge $\times 1$-inch needle to the syringe filter of the gas source.

(ii) Adjust pressure regulator to $150 \mathrm{kPa}$ and open the main gas flow $\left(\mathrm{CH}_{4}: \mathrm{CO}_{2}\right)$ to purge the system.

(iii) Inject the needle through the sterilized stopper of the culture bottle and open the stopcock to allow gas inflow. 
(iv) To flush the headspace, inject a second needle (26-gauge $\times 1$-inch) for gas outflow.

(v) Flush the headspace for 1-3 $\mathrm{min}$, remove outflow needle and allow the pressure to build up before closing the stopcock and removing the inflow needle.

(B) Headspace filling

(i) Attach a Luer three-way-stopcock to the syringe filter of the gas source.

(ii) Attach a 60-ml disposable syringe to the second port of the three-way stopcock.

(iii) Attach a needle (26-gauge $\times 1$-inch) to the third (male) port of the stopcock.

(iv) Adjust the gas flow to $\sim 0.2$ bar and flush the syringe with the hydrocarbon gases at least three times by filling the complete volume of the syringe and discarding the gas through the attached needle. Therefore, fill the syringe with gas by adjusting the stopcock to allow the gas flow from the gas source into the syringe. Discard the gas volume by adjusting the stopcock to allow gas to move out of the syringe via the needle and press the syringe plunger.

(v) Sterilize the stopper of the culture bottle.

(vi) Then fill the syringe with the defined gas volume (i.e., $56 \mathrm{ml}$ for 100-kPa gas pressure in a 156-ml bottles filled with $100 \mathrm{ml}$ of liquid phase and a $56-\mathrm{ml}$ headspace) and adjust the valve of the three-way stopcock to allow gas flow between the syringe and the needle. Now inject the needle through the stopper and press the gas into the culture bottle. $\triangle$ CRITICAL STEP Before addition of hydrocarbon gas, we recommended releasing overpressure from the bottles by introducing a short needle (20-gauge $\times 1$ 1/2-inch or 23-gauge $\times 1$ 1/4-inch) through the stopper to make this step easier.

\section{Incubation of culture bottles}

9| Transfer the culture bottles to an incubator. Shake the bottles by hand for 5-10 s once a week to avoid compaction of the slurry and to equilibrate the medium and the headspace.

$\triangle$ CRITICAL STEP If possible, set a shutdown temperature $5{ }^{\circ} \mathrm{C}$ above the incubation temperature at the incubator to avoid loss of enrichment cultures in case of a thermostat malfunction.

\section{Tracking of metabolic activity in the enrichment cultures TIMING $1 \mathrm{~h}$ for ten samples}

$\Delta$ CRITICAL Sulfide concentrations (Steps 10-16) should be determined at the start of the incubation, and at intervals of 2-4 weeks, depending on the initial sulfide production and its development over time. Shake all culture bottles gently 6-15 h before measurement and keep culture bottles in the incubator until measurements are performed. The settling time can be reduced after cultures no longer contain large amounts of sediment particles.

10| Transfer $4 \mathrm{ml}$ of copper sulfate solution to a test tube. Prepare as many test tubes as samples to be measured, plus one for a blank measurement.

11| Turn on the photometer that has been calibrated with sulfide standards; make sure to set it to $480 \mathrm{~nm}$ and perform a zero-point calibration with $4 \mathrm{ml}$ of copper sulfate solution in a 2.5 - $\mathrm{ml}$ cuvette (it holds all $4 \mathrm{ml}$ ).

12| Remove the culture bottles from the incubator (avoid shaking them, in particular when they still contain sediment particles) and place them next to the photometer. Sterilize the stopper surface by igniting a drop of ethanol ( $96 \%(\mathrm{vol} / \mathrm{vol}))$ on it. ! CAUTION When working with flammable elements, use protective googles and avoid wearing gloves.

13 Inject a short needle (26-gauge $\times 1$-inch) attached to a 1-ml syringe through one side of the stopper. Tilt the culture bottle to quickly withdraw $\sim 300 \mu \mathrm{l}$ of medium and pull out the syringe containing the sample.

14| Quickly remove any bubbles and inject exactly $100 \mu$ l of sample into the test tube.

15| Quickly seal the test tube (e.g., with a piece of Parafilm), mix by inverting the tube once and decant the contents into a 2.5 - $\mathrm{ml}$ cuvette (it holds all $4 \mathrm{ml}$ ). Immediately measure the sample in the photometer. Discard the sample (i.e., pour it into a bottle for dissolved metal waste).

? TROUBLESHOOTING

16| To proceed with the next culture bottle, repeat Steps 14-16 using a new syringe, needle and test tube.

Maintenance and dilution of enrichment cultures (when sulfide concentrations exceed maximum value)

17| The procedure for maintenance and continuation of enrichment cultures should be carried out when sulfide concentrations exceed $15 \mathrm{mM}$ or sulfide production rates start to decline because of product inhibition. This is done by exchanging the enrichment medium and optionally diluting the enrichment material (i.e., biomass and/or sediment particles) within an anoxic chamber (option A) or by transferring a portion of the enrichment material to serum bottles 
with fresh anoxic medium (option B; see also Supplementary Video 4). Option A is preferable when the culture bottles still contain substantial amounts of sediment or when large consortia are formed, because then the sample cannot be evenly distributed using option B. Option B does not require the use of an anoxic chamber and should be chosen when there is little sediment remaining in the culture. Moreover, option B reduces the risk of cross-contamination. The amount of transferred enrichment material depends on the growth rates/doubling times of the culture (i.e., very slow-growing methanotrophic cultures should be diluted by a factor of 2-4).

$\triangle$ CRITICAL To reduce the risk of losing a complete sample set, always work with a subset of your samples and store remaining samples from earlier dilutions in bottles under anoxic conditions at room temperature. Enrichments can be restarted from these samples after months.

(A) Enrichment medium exchange and dilution within an anoxic chamber $\bigcirc$ TIMING $3 \mathrm{~h}$ for ten samples

$\Delta$ CRITICAL Step 17A(i-v) is only required if medium is exchanged while keeping the complete biomass in the bottle. The sulfidic medium can be removed in the chamber, but by removing the supernatant outside of the chamber, the amount of sulfide transferred to the chamber is reduced. Prepare anoxic medium in Duran flasks with side opening (Step 1B).

(i) Let the enrichment material settle for $\sim 12 \mathrm{~h}$ before starting the procedure (i.e., do not shake the culture bottles during this time). Connect a long needle (21-gauge $\times 4$ 3/4-inches) to a Luer one-way stopcock with attached tube. Use forceps to inject the needle through the stopper of the culture bottle. Submerge the needle until it is slightly above the surface of the enrichment material (i.e., sediment particles, biomass, inorganic precipitates).

(ii) Open the stopcock and collect the outflowing medium in a dedicated waste beaker. While the culture bottle is under pressure, the medium will flow out.

(iii) Once no overpressure is left, inject a short needle (20-gauge $\times 11$-2-inch) connected via a stopcock plus tubing to a $\mathrm{N}_{2}: \mathrm{CO}_{2}$ gas source. Set the pressure regulator to $100 \mathrm{kPa}$ and open the stopcock to allow gas inflow into the culture bottle. Do not use pressures higher than $200 \mathrm{kPa}$ in order to reduce the risk of breaking the glass bottles.

! CAUTION The removed medium is strongly sulfidic and therefore toxic when inhaled. Work under a fume hood.

(iv) When the desired medium volume is removed, purge the headspace for additional 2 min to remove hydrocarbon gases and excess sulfide to avoid their accumulation in the anoxic chamber.

(v) Keep the medium waste under a fume hood until the contained sulfide is oxidized. To rapidly oxidize sulfide, add hydrogen peroxide (30\%, $10 \mathrm{ml}$ per liter medium). Once oxidized (i.e., the color has changed to yellow or pinkish), dispose of the medium waste in the sink.

(vi) Transfer the following material to an anoxic chamber: anoxic medium in a Duran flask, culture bottles, autoclaved butyl rubber stoppers, disposable plastic pipettes and pipette controller, decapping tongs, sterile serum bottles (if dilution of the enrichment culture is to be performed) and disposable scrapers.

I CAUTION Always loosen the side cap of the Duran flask for the transfer to the anoxic chamber.

(vii) Use the decapping tongs to open the culture bottles. (Optional) If the enrichment material (i.e., the biomass) attaches to the glass of the culture bottle, use a sterile disposable scraper to detach it.

(viii) If the enrichment material needs to be diluted, transfer equal volumes to fresh bottles (e.g., for a 1:1 dilution, split into two bottles) using a sterile pipette plus a pipette controller and fill up with medium to the desired volume (e.g., $100 \mathrm{ml}$ ). If no dilution is required, fill up the culture bottle with fresh medium to the desired volume.

(ix) Close the culture bottles with sterile butyl rubber stoppers. Handle the stoppers with sterile tweezers.

(x) Remove the culture bottles and all equipment from the anoxic chamber. Cap the culture bottles with aluminum crimp caps using capping tongs. Add substrate to the culture bottles according to Step 8 and continue with incubation (Step 9).

\section{? TROUBLESHOOTING}

(B) Enrichment culture transfer without an anoxic chamber $\bigcirc$ TIMING $4 \mathrm{~h}$ for ten samples

(i) Prepare serum bottles prefilled with medium (Step $1 \mathrm{~A}(\mathrm{i}-\mathrm{xvi})$ or Step $1 \mathrm{~B}(\mathrm{i}-\mathrm{xvi}))$. Release overpressure from these bottles by introducing a short needle (20-gauge $\times 1$ 1/2-inchor 23-gauge $\times 11 / 4$-inch) through the stopper.

(ii) (Optional) Often the cells in enrichment cultures attach to the bottle walls and need to be detached before the transfer of the enrichment material. To detach the cells, remove overpressure from the culture bottle by piercing the stopper with a short needle, opening the bottle using the decapping tool under sterile conditions (e.g., next to the flame) and immediately introducing a needle (20-gauge $\times 1$ 1/2-inch) connected via stopcock plus tubing to an anoxic gas $\left(\mathrm{N}_{2}\right.$ : $\mathrm{CO}_{2}$ ) source. Open stopcock for gas inflow to prevent oxygen influx during the handling of the open culture bottle. ! CAUTION Work under a fume hood while handling strongly sulfidic liquids.

(iii) (Optional) Detach the biomass from the bottom and the walls of the culture bottle using a sterile disposable scraper. Seal the culture bottle with a sterile butyl rubber stopper and an aluminum crimp cap. Connect a needle (20-gauge $\times 11$ /2-inch) via stopcock plus tubing to an anoxic gas $\left(\mathrm{N}_{2}: \mathrm{CO}_{2}\right)$ source with $150-\mathrm{kPa}$ gas pressure. Inject the needle into the bottle to create overpressure.

! CAUTION Do not exceed a gas pressure of $200 \mathrm{kPa}$ in order to avoid breaking the glass bottles. This overpressure allows easier sampling in the next step and avoids oxygen penetration. 
(iv) Mix the culture bottle well and sterilize the stopper surface before retrieving a subsample. Using a plastic syringe with a Luer-Lock tip plus a thick needle (20-gauge $\times 1$ 1/2-inch or 23 -gauge $\times 1$ 1/3-inch), withdraw the desired enrichment volume (e.g., $20 \mathrm{ml}$ ) and transfer it to a serum bottle filled with fresh anoxic medium (e.g., $80 \mathrm{ml}$ ).

(v) Add substrates to the culture bottles (Step 8) and continue incubation (Step 9). ? TROUBLESHOOTING

\section{Dry weight determination for initial slurry $\bigcirc$ TIMING 2 h over $2 \mathrm{~d}$}

18| Weigh three appropriate centrifuge tubes $(50 \mathrm{ml})$.

19| Transfer the same amount of the initial slurry (Step 4) to each of the pre-weighed tubes.

! CAUTION the volume of the subsample must be defined exactly (i.e., $25 \mathrm{ml}$ ).

20| Centrifuge the subsample (i.e., 2,000 g, $10 \mathrm{~min}$, room temperature), decant the supernatant and dry the pellet in an oven $\left(60^{\circ} \mathrm{C}\right)$ until the weight remains constant (e.g., for $\left.\sim 3 \mathrm{~d}\right)$.

21| Weigh the tube with the pellet and determine the dry weight of the pellet.

The determined dry weight can be used to normalize all measurements and compare metabolic activity of early enrichment cultures (i.e., sulfate reduction per $g_{\text {dry_weight }}$ of sediment).

\section{Calculation of activity doubling from sulfide production rates $\bigcirc$ TIMING $1 \mathrm{~h}$}

22 Use a spreadsheet program such as Excel to plot in a semi-logarithmic manner the sulfide concentrations [HS-] from at least six time points measured in the culture ( $\ln \left[\mathrm{HS}^{-}\right]$versus sampling time). Use the statistical tools of the program to calculate the exponential function of their relation representing the function $\left[\mathrm{HS}^{-}\right]_{(\mathrm{t})}=\left[\mathrm{HS}^{-}\right]_{(0)} \times e^{K \times \mathrm{t}}$, where $K$ is the slope of the logarithmic relationship and represents the change of sulfide concentration over time. From this slope, the time of activity doubling $\left(T_{\mathrm{d}}\right)$ can be inferred based on the function $T_{\mathrm{d}}=\ln (2) / K$. The time of activity doubling meets the doubling times of the hydrocarbon-oxidizing community members.

\section{Collection and preservation of enrichment material for subsequent analysis}

23| The procedure for collecting material from the enrichment culture and its preservation depends on the desired downstream analysis. Proceed as follows to collect and preserve samples for DNA extraction (option A), FISH (option B), RNA extraction (option C) or metabolomics analysis (option D). The required volume of material depends on the activity, expected biomass and stage of the enrichment (e.g., sediment-containing or sediment-free), as well as on the approach desired for analysis. As a general recommendation, if possible, material should be sampled from well-growing, active enrichment cultures. We recommend comparing the microbial compositions of the initial slurry ( $T_{0}$, see Step 4$)$ with those of the well-established cultures (minimum three successful transfers). However, intermediate analysis can be performed in order to monitor and study the development of the culture.

RNA extraction (option C; Supplementary Video 5) should be done on active enrichment cultures during the exponential growth phase (enrichment cultures should show a sulfide production $\geq 0.1 \mathrm{mmol}$ per liter per day, and sulfide concentrations should be $<12 \mathrm{mM}$, to ensure sampling during the exponential growth phase). For RNA extraction, autoclave all material with direct sample contact (i.e., filtration system, glass Petri dishes, pipette tips and metallic tweezers) at $121^{\circ} \mathrm{C}$ for 40 min. Clean lab space and instruments with RNaseZAP.

\section{(A) Collection and preservation of material for DNA extraction $\bigcirc$ TIMING $1 \mathrm{~h}$ for four samples}

(i) Mix the culture bottle well and sterilize the stopper surface before retrieving a subsample. Using a plastic syringe with Luer-Lock tip plus a thick needle (20-gauge $\times 1$ 1/2-inch or 23-gauge $\times 1$ 1/4-inch), withdraw the desired enrichment volume (e.g., $50 \mathrm{ml}$ ) and transfer it to a sterile tube (e.g., a 50-ml Falcon tube).

(ii) Close tube and centrifuge the subsample down (i.e., 5,000g, $4^{\circ} \mathrm{C}, 10 \mathrm{~min}$ ).

(iii) Discard supernatant and remove the residual liquid with a pipette.

(iv) Store the pellet at $-20^{\circ} \mathrm{C}$. Frozen material for DNA extraction can be stored for years.

\section{(B) Collection and preservation of material for FISH $\bigcirc$ TIMING 2-3 $\mathrm{h}$}

(i) Mix the culture bottle well and sterilize the stopper surface before retrieving a subsample. Using a plastic syringe with a Luer-Lock tip plus a thick needle (20-gauge $\times 1$ 1/2-inch or 23 -gauge $\times 11 / 4$-inch), withdraw the desired enrichment volume (e.g., $2 \mathrm{ml}$ ) and transfer it to a sterile tube (e.g., 2-ml Eppendorf tube).

(ii) Add $37 \%$ formaldehyde solution to achieve a final formaldehyde concentration of $2 \%$ (e.g., to a 2-ml subsample, add $108 \mu \mathrm{l}$ of $37 \%$ formaldehyde solution). 
(iii) Mix well and incubate for $1 \mathrm{~h}$ at room temperature or overnight $(12 \mathrm{~h})$ at $4{ }^{\circ} \mathrm{C}$.

$\triangle$ CRITICAL STEP Prolonged incubation will lead to an overfixation and thus reduced accessibility of cells for oligonucleotide probes.

(iv) Centrifuge the subsample (e.g., 8,000g, $4^{\circ} \mathrm{C}, 5 \mathrm{~min}$ ), decant the supernatant, add $1 \times$ PBS (e.g., $2 \mathrm{~mL}$ of $1 \times$ PBS to a pellet from a 2-ml subsample) and resuspend the pellet. Repeat this washing procedure twice.

(v) Centrifuge the subsample (e.g., 8,000g, $4^{\circ} \mathrm{C}, 5 \mathrm{~min}$ ), decant the supernatant, add a 1:1 mixture of $1 \times$ PBS:99\% ( $\mathrm{vol} / \mathrm{vol}$ ) ethanol (e.g., $2 \mathrm{ml}$ of $1 \times \mathrm{PBS}: \mathrm{EtOH}$ to a pellet from a 2-ml subsample) to achieve a final concentration of $50 \%(\mathrm{vol} / \mathrm{vol})$ ethanol in $1 \times$ PBS, and resuspend the pellet.

(vi) Store the subsample in PBS:EtOH solution at $-20^{\circ} \mathrm{C}$. Samples can be stored for years.

\section{? TROUBLESHOOTING}

(C) Collection and preservation of material for RNA extraction using RNAlater $\bigcirc$ TIMING 2-3 $\mathrm{h}$

(i) Fill a sterile $50-\mathrm{ml}$ syringe with $50 \mathrm{ml}$ of RNAlater and heat it to the enrichment's incubation temperature (e.g., by placing it in an incubation oven).

(ii) Fill a water bath and heat the water to the temperature used for incubation of the enrichment culture. ! CAUTION Cultures contain large amounts of toxic sulfide. Work under a fume hood when performing Step 23C(iii-x).

(iii) Place the culture bottle in the water bath (Fig. 3). Make sure that $\sim 2 / 3$ of the bottle is submerged but do not submerge the bottle completely. Sterilize the stopper surface. Let the biomass and any inorganic precipitates or sediment particles settle.

$\triangle$ CRITICAL STEP Move the bottle as little as possible during the rest of the procedure to avoid resuspension of the settled material.

(iv) Connect a Luer one-way stopcock plus a needle (20-gauge $\times 11 / 2$-inch) to a $\mathrm{CO}_{2}: \mathrm{N}_{2}(90: 10)$ gas source adjusted to $100 \mathrm{kPa}$. Connect the culture bottle to the gas source by injecting the needle through the stopper and then open the stopcock for gas inflow. Attach a long needle (21-gauge $\times 43 / 4$-inches) to a Luer one-way stopcock connected to sterile PVC male Luer-Lock tubing. Ensure the stopcock is closed and use sterile forceps to inject the long needle through the stopper of the culture bottle. Keep the needle tip close to the surface of the medium.

(v) Open the stopcock in front of the long needle to withdraw the medium using the overpressure created by the gas inflow. Collect the outflowing medium in a beaker. While the medium flows out, make sure to continuously move the long needle down to keep it submerged but close to the medium surface in order to limit disturbance of the settled material. Remove $\sim 90-95 \%$ of the medium volume, but avoid removal of the cell material.

! CAUTION The supernatant has high sulfide concentrations. Collect and treat supernatant as described above (Step 17A(v)).

(vi) Move the long needle to a position above the remaining medium and immediately inject the pre-warmed RNAlater with a short, thick needle (20-gauge $\times 11$ /2-inch). Remove the long needle and allow the pressure to build up before closing the inflow stopcock and removing the short needle.

(vii) Incubate the bottles in the water bath for $30 \mathrm{~min}$.

- PAUSE POINT Samples can be stored at $-20{ }^{\circ} \mathrm{C}$ for months if necessary.

(viii) Setup of filtration system. Place the vacuum filtration device on a Duran bottle. Moisten both sides of a support filter (47-mm diameter, $0.45-\mu \mathrm{m}$ pore size) by submerging it in a Petri dish filled with DEPC water. Place the moistened filter on the vacuum filtration device. Using sterile tweezers, place a polycarbonate filter (47-mm diameter, 0.2- $\mu \mathrm{m}$ pore size) on top of the support filter. Avoid wrinkling of the filters. Connect the filtration device to a vacuum system and screw in the funnel of the filter device.

(ix) Release overpressure from the bottle using a short needle (20-gauge $\times 1$ 1/2-inch or 23-gauge $\times 1$ 1/4-inch) and open the bottle using decapping tongs. Resuspend the material in the culture bottle by mixing or by using a sterile cell scraper.

(x) Turn on the vacuum system. Pour the bottle contents slowly onto the filter so the material is deposited on it. Once the liquid is completely removed, transfer the polycarbonate filter to a sterile Petri dish using sterile tweezers. Cut the filter into four pieces using a sterile disposable scalpel. Collect and treat the filtered medium as described above (Step 17A(v)).

(xi) Use sterile tweezers to combine all filter pieces in a Lysis Matrix E tube pre-filled with $600 \mu \mathrm{l}$ of RNA lysis buffer from the Quick-RNA Miniprep Kit. Keep the sample tube on ice.

(xii) Lyse the sample in a bead-beating machine, applying two cycles of $6 \mathrm{~m} / \mathrm{s}$ for $20 \mathrm{~s}$. I CAUTION To ensure safe use of the bead-beating machine, follow the manufacturer's instructions; i.e., to avoid overheating, the described instrument needs to cool for at least 5 min between the two cycles.

(xiii) For RNA extraction, we recommend continuing extraction as detailed in the Quick-RNA Miniprep Kit instructions. ? TROUBLESHOOTING 


\section{(D) Collection and lysis of cells for metabolome analysis $\bigcirc$ TIMING 2-3 $\mathrm{h}$}

$\Delta$ CRITICAL Samples for metabolome analysis should be taken from a dense enrichment culture during the exponential growth phase; sulfide concentration should not be higher than 12-15 mM. The enrichment culture should be kept at the incubation temperature during the sampling procedure. All steps should be performed rapidly. Avoid breaks.

(i) Mix the culture bottle well and sterilize the stopper surface before retrieving a subsample. Using a plastic syringe with a Luer-Lock tip plus a thick needle (20-gauge $\times 1$ 1/2-inch), withdraw the desired enrichment volume (minimum $=20 \mathrm{ml}$ ) and transfer it to a sterile $50-\mathrm{ml}$ centrifuge tube.

! CAUTION Sulfide will flush out; work under a fume hood. Alternatively, release the overpressure in the culture bottle by inserting a needle through the stopper. Remove the rubber stopper of the culture bottle, and, under a gentle stream of $\mathrm{N}_{2}: \mathrm{CO}_{2}(90: 10)$ or in an anoxic chamber, collect a 20 - $\mathrm{ml}$ culture volume using a 10-ml pipette with a wide tip (i.e., cut the tip of a normal pipette tip).

(ii) Centrifuge for $10 \mathrm{~min}$ at $16,000 \mathrm{~g}$ and $4^{\circ} \mathrm{C}$.

(iii) Remove supernatant with a pipette plus a pipette controller.

I CAUTION The supernatant has high sulfide concentrations. Work in a fume hood. Collect and treat the supernatant as described above (Step 17A(v)).

(iv) Wash the cells with $1 \mathrm{ml}$ of $100 \mathrm{mM}$ ammonium bicarbonate buffer and gently resuspend the cells in the buffer by slow up-and-down pipetting.

$\triangle$ CRITICAL STEP It is essential that the integrity of the cells be maintained until planned lysis in the solvent mix; otherwise, metabolites will be released and discarded in the following steps.

(v) Transfer to 2-ml centrifuge tubes. Verify the cells for signs of lysis under a light microscope. If needed, adjust the concentration of the buffer, or test other buffers recommended for electrospray ionization (e.g., ammonium acetate).

(vi) Centrifuge for $10 \mathrm{~min}$ at $16,000 \mathrm{~g}$ and $4^{\circ} \mathrm{C}$. Discard the buffer and repeat the washing twice.

(vii) Add $1 \mathrm{ml}$ of solvent mix (acetonitrile:methanol:water 40:40:20 (vol/vol/vol)). Here the cell lysis starts. Vortex briefly to resuspend the cells. Add $0.3-0.5 \mathrm{~g}$ of glass beads per tube.

(viii) Lyse the cells in a bench-top bead-based homogenizer using five cycles of 2,000 r.p.m. for $50 \mathrm{~s}$, with a 15-s pause between cycles.

(ix) Remove the tubes from the homogenizer and allow the beads to settle. Collect the liquid in a clean tube.

(x) To remove cell debris and residual glass beads, centrifuge for $10 \mathrm{~min}$ at $16,000 \mathrm{~g}$ at $4^{\circ} \mathrm{C}$. Collect the clear supernatant in 2-mL Zinsser NA glass vials and close with Teflon-lined screw caps. Place the samples at $-20{ }^{\circ} \mathrm{C}$ until analysis. At this temperature, samples can be stored indefinitely.

? TROUBLESHOOTING

\section{? TROUBLESHOOTING}

Troubleshooting advice can be found in Table 1 (see Fig. 4).

TABLE 1 | Troubleshooting table.

\begin{tabular}{|c|c|c|c|}
\hline $\begin{array}{l}\text { Step } 1 A \text { (viii), } \\
1 B(x i)\end{array}$ & $\begin{array}{l}\text { Medium cannot be reduced, } \\
\text { as indicated by a pinkish } \\
\text { color (Fig. } 4 \text { ) }\end{array}$ & Influx of oxygen & $\begin{array}{l}\text { Add a small amount of dithionite to reduce the medium; } \\
\text { check the gas inflow and ensure that the medium is } \\
\text { supplied with an anoxic headspace (i.e., when } \\
\text { connected to the pressure regulator, check that } \\
\text { overpressure builds up when all openings of the bottle } \\
\text { are closed); prepare new medium and check the setup } \\
\text { of the Widdel flask or Duran bottle (i.e., glass openings } \\
\text { are not cracked, stoppers seal properly, clamps seal } \\
\text { tubing tightly) }\end{array}$ \\
\hline
\end{tabular}

Medium turns yellow (Fig. 4) Formation of elemental sulfur due to oxygen influx
Irreversible; prepare new medium. Ensure that the medium is supplied with an oxygen-free headspace (i.e., $\mathrm{N}_{2}$ or $\mathrm{N}_{2}: \mathrm{CO}_{2}$ gas) and that all openings can be properly sealed (e.g., glass openings are not cracked) 
TABLE 1 | Troubleshooting table (continued).

\begin{tabular}{ll} 
Step & Problem \\
\hline & Precipitation of gray crystals \\
in the medium and/or \\
formation of a grayish surface \\
layer (black precipitates/ \\
metal sulfide precipitation is \\
normal with time)
\end{tabular}
Step $7 \quad$ Medium in initial incubation turns pink
Very little/no sulfide production; stoppers are not gas-tight

No sulfide formation in the freshly incubated sediment

\begin{abstract}
No/decreased sulfide production in the culture after medium exchange/dilution
\end{abstract}

Step $17 \mathrm{~A}(\mathrm{x}), \quad$ No or little growth after 17B(v) transfer

Step 23B(vi) Filters appear milky under the microscope

Step 23C(xiii) Recovery of no/little or highly degraded RNA

Step $23 D(x)$
Possible reason

$\mathrm{pH}$ might be too high or $\mathrm{CO}_{2}$ is missing from the gas phase

Microorganisms with the required metabolism are low in abundance or even absent in the source material

Composition or $\mathrm{pH}$ of the medium is incorrect; insufficient time to detect activity; hydrocarbon substrate has not been supplied or has been completely consumed; stoppers are not tight and sulfide or hydrocarbon substrates leaked out

Most cells attached to the walls of the incubation bottle, therefore only little biomass was transferred

Formation of carbonate precipitates in the subsample

Equipment might be contaminated with RNases; the amount of material sampled was insufficient The amount of material was

\section{Solution}

Irreversible; prepare new medium. Ensure that the medium is supplied with a $\mathrm{CO}_{2}$-containing (e.g., $\mathrm{N}_{2}: \mathrm{CO}_{2}$ gas) headspace once the bicarbonate buffer has been added

Reduce the medium with small amounts of freshly prepared sodium dithionite solution; ensure stoppers are made of gas-tight material (e.g., butyl rubber); check quality of the stoppers (i.e., no fissures in the rubber material); replace the stoppers with new ones

Prolong the incubation (i.e., check for activity every few months) or use an alternative source material

Check pH; prolong the incubation; exchange medium, supply (more) hydrocarbon substrate; check quality of the stoppers and, if necessary, replace the stoppers

Before transfer, open the culture bottle and scratch the cells from the walls using a sterile disposable scraper. Work under anoxic conditions Use the stored bottles from earlier enrichment stages to repeat the culture transfer procedure

Incubate a subsample with $10 \mathrm{mM} \mathrm{HCl}$ (final conc.) for 1-5 min before filtration to dissolve carbonate crystals

Repeat RNA extraction. If possible, increase the amount of material sampled for RNA extraction. This might be particularly important when the enrichment culture has only low activity. Ensure that all equipment has been cleaned with RNaseZAP and autoclaved for $45 \mathrm{~min}$ at $121^{\circ} \mathrm{C}$. Prepare fresh DEPC-treated water

Use more/more-concentrated cells; harvest at a later insufficient; cells lysed during stage; test other washing buffers washing steps 
Step 17, transfer/dilution of enrichment cultures: 3-4 h for ten samples Steps 18-21, dry weight determination and doubling time calculation: $2 \mathrm{~h}$ hands-on over $2 \mathrm{~d}$

Step 22, calculation of activity doubling from sulfide production rates: $1 \mathrm{~h}$

Step 23A, collection and sample preservation for DNA extraction: $1 \mathrm{~h}$ for four samples

Step 23B, collection and sample preservation for FISH: 2-3 h

Step 23C, collection and sample preservation for RNA extraction: $2-3 \mathrm{~h}$ per sample

Step 23D, collection and lysis of cells for metabolome analysis: 2-3 h per sample

Box 1, photometer calibration for sulfide measurements: $30-60 \mathrm{~min}$

Box 2, preparation of anoxic medium: 20 min

\section{ANTICIPATED RESULTS}

This protocol enables the enrichment of anaerobic hydrocarbon-degrading microorganisms from hydrocarbon-rich sulfidic sediments in a cost-efficient and low-maintenance batch-cultivation approach. Using a suitable inoculum activity, doubling times below those obtainable using flow-through reactors can be achieved (Table 2). This protocol describes the procedure to enrich microorganisms responsible for the anaerobic oxidation of specific gaseous hydrocarbons. The successful establishment of such enrichment cultures depends on (i) the selection of suitable sediment material (i.e., sediments harboring a microbial community with metabolic potential to degrade hydrocarbons) and (ii) the selection of enrichment conditions (i.e., hydrocarbon substrate and incubation temperature selected according to in situ data from the sampling site). Using hydrothermally heated sediments from the Guaymas Basin, we established sediment-free enrichment cultures within 1 year (Fig. 5). The provided hydrocarbon (i.e., methane or butane) and the incubation temperature (i.e., $37-60{ }^{\circ} \mathrm{C}$ ) determined which organisms were predominantly enriched. Enrichment cultures supplied with methane are dominated by consortia of ANME-1/Ca. Desulfofervidus auxilii at $60^{\circ} \mathrm{C}$ or ANME-1/Seep-SRB2 at $37{ }^{\circ} \mathrm{C}$, and enrichment cultures provided with butane at $50{ }^{\circ} \mathrm{C}$ are dominated by consortia of $\mathrm{Ca}$. Syntrophoarchaeum/ $\mathrm{Ca}$. Desulfofervidus auxilii. The high relative abundance of syntrophic hydrocarbon-degrading consortia in these enrichment cultures facilitated their extensive molecular and

TABLE 2 | Comparison of published approaches for the enrichment of anaerobic methanotrophic archaea.

\begin{tabular}{|c|c|c|c|c|}
\hline & $\begin{array}{c}\text { Unpressured } \\
\text { flow-through reactor }\end{array}$ & $\begin{array}{c}\text { Pressurized } \\
\text { flow-through reactors }\end{array}$ & $\begin{array}{l}\text { Pressurized batch } \\
\text { incubation }\end{array}$ & $\begin{array}{l}\text { Low-pressure batch } \\
\text { incubation }\end{array}$ \\
\hline Reference & 61 & 51 & 60 & 50 \\
\hline Activity/doubling times & No growth observed & $\begin{array}{l}\text { Down to 2-month } \\
\text { doubling time; strongly } \\
\text { increased as compared } \\
\text { with other low-tempera- } \\
\text { ture systems }\end{array}$ & $\begin{array}{l}\text { Doubling time = } 7 \text { months; } \\
\text { growth rates are } \\
\text { comparable to } \\
\text { low-temperature, } \\
\text { low-pressure incubations }\end{array}$ & $\begin{array}{l}\text { Doubling time down } \\
\text { to } 50 \mathrm{~d}\end{array}$ \\
\hline Maintenance effort & High & Very high & Medium & Low \\
\hline Cost of the setup & Medium & $\begin{array}{l}\text { Very high costs for high- } \\
\text { pressure pumps and setup }\end{array}$ & $\begin{array}{l}\text { High costs for pressure } \\
\text { vessels and pumps }\end{array}$ & Low \\
\hline Cultivation success & $\begin{array}{l}\text { Activity kept constant } \\
\text { over } 180 \mathrm{~d}\end{array}$ & $\begin{array}{l}\text { Strong increase in } \\
\text { activity possible }\end{array}$ & $\begin{array}{l}\text { Ten times increased rates, } \\
\text { within }>2 \text { years }\end{array}$ & $\begin{array}{l}\text { Sediment-free cultures } \\
\text { reached within } \sim 1 \text { year }\end{array}$ \\
\hline Enriched archaea & Not assessed & ANME-2 & ANME-2 & $\begin{array}{l}\leq 20^{\circ} \mathrm{C}: \text { ANME-2 } \\
37-60^{\circ} \mathrm{C}: \text { ANME-1 }\end{array}$ \\
\hline Suggested application & Physiological tests & $\begin{array}{l}\text { Physiological tests, opti- } \\
\text { mization of growth yields }\end{array}$ & $\begin{array}{l}\text { Biomass increase, } \\
\text { physiological tests, } \\
\text { piezophilic organisms }\end{array}$ & $\begin{array}{l}\text { Enrichment to sediment- } \\
\text { free state, enrichment of } \\
\text { specific strains, multiple } \\
\text { substrate tests }\end{array}$ \\
\hline
\end{tabular}




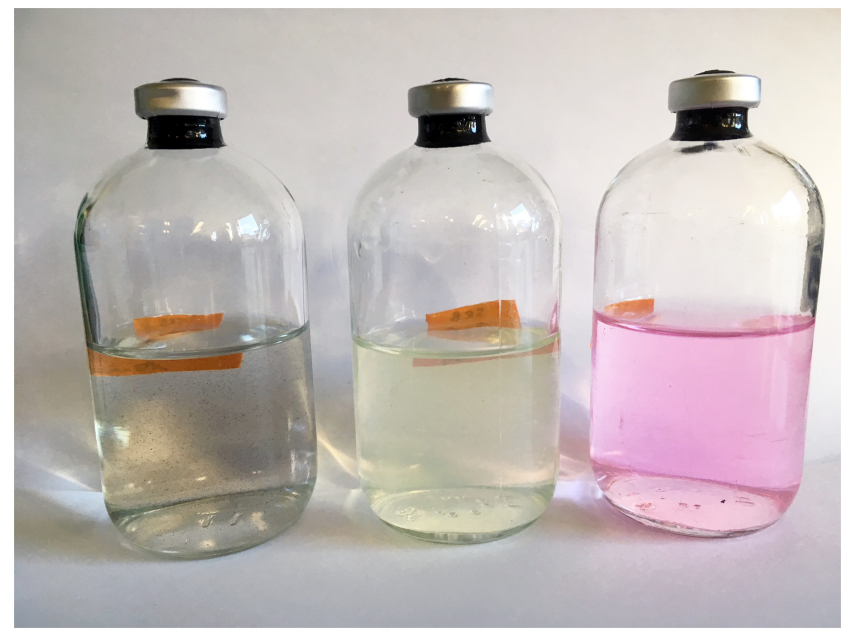

Figure 4 | The culture medium in serum bottles. (Left) Medium prepared under strictly anoxic conditions appears colorless with small black precipitates. (Middle) Yellowish medium indicates formation of elemental sulfur in the culture medium due to minor oxygen contamination.

(Right) Medium has turned pink due to an increase of redox potential by contamination with more oxygen.

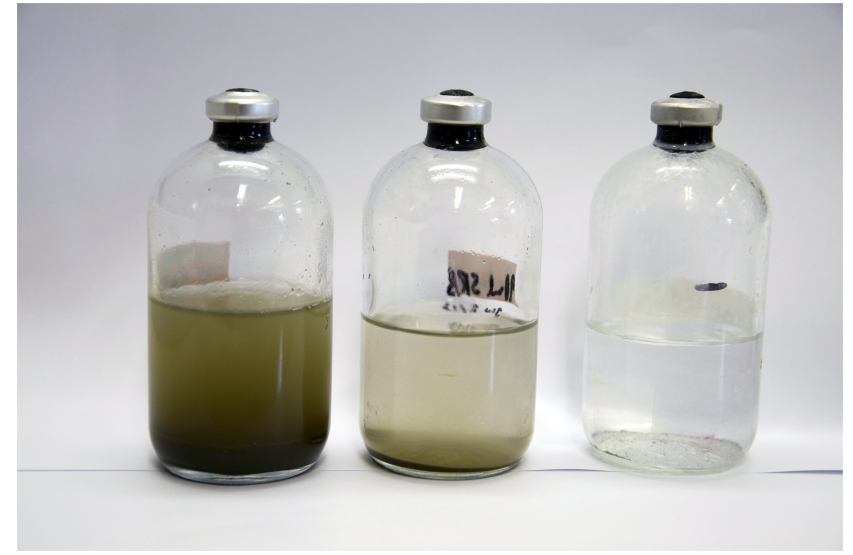

Figure 5 | Appearance of enrichment cultures during cultivation. (Left) The freshly incubated sediment slurry is dark brown. (Middle) After two dilution steps/transfers, sediment content is strongly reduced. (Right) After five or more transfers, enrichment cultures appear sediment-free, and clumps of microbial consortia become visible to the eye.

physiological characterization using culture-dependent and culture-independent approaches. For RNA sampling, the optimized anoxic fixation procedure at cultivation temperatures yielded much higher amounts and quality of RNA than in previously described standard procedures.

Note: Any Supplementary Information and Source Data files are available in the online version of the paper.

ACKNOWLEDGMENTS We thank $F$. Widdel for his advice and guidance in regard to cultivation and the development of this protocol. We are indebted to R. Appel, S. Menger and T. Holler for their contributions to the maintenance of the enrichment cultures and their suggestions for further improvement of our protocol. This protocol was tested with samples collected during Guaymas expedition AT15/45 in December 2016, Chief Scientist A. Teske, NSF grant BI0OCE 1357238. This work was supported by the DFG Excellence Cluster MARUM and a Leibniz Grant to A. Boetius.

AUTHOR CONTRIBUTIONS R.L.-P., V.K., F.M. and G.W. contributed equally to the design, validation and optimization of this protocol. R.L.-P., V.K. and G.W. prepared the figures; R.L.-P. and G.W. prepared the supplementary videos. R.L.-P., V.K., F.M. and G.W. cooperatively wrote and edited the manuscript.

COMPETING INTERESTS The authors declare no competing interests.

Reprints and permissions information is available online at http://www.nature. $\mathrm{com} /$ reprints/index.html. Publisher's note: Springer Nature remains neutral with regard to jurisdictional claims in published maps and institutional affiliations.

1. Handelsman, J. Metagenomics: application of genomics to uncultured microorganisms. Microbiol. Mol. Biol. Rev. 68, 669-685 (2004).

2. Edwards, T. \& McBride, B. New method for the isolation and identification of methanogenic bacteria. Appl. Microbiol. 29, 540-545 (1975).

3. Gieg, L.M., Davidova, I.A., Duncan, K.E. \& Suflita, J.M. Methanogenesis, sulfate reduction and crude oil biodegradation in hot Alaskan oilfields. Environ. Microbiol. 12, 3074-3086 (2010).

4. Strous, M., Heijnen, J., Kuenen, J.G. \& Jetten, M. The sequencing batch reactor as a powerful tool for the study of slowly growing anaerobic ammonium-oxidizing microorganisms. Appl. Microbiol. Biotechnol. 50, 589-596 (1998).

5. Wegener, G., Krukenberg, V., Riedel, D., Tegetmeyer, H.E. \& Boetius, A. Intercellular wiring enables electron transfer between methanotrophic archaea and bacteria. Nature 526, 587-590 (2015).
6. Winogradsky, S. Sur les organismes de la nitrification. Comptes Rendus Acad. Sci. 110, 1013-1016 (1890).

7. Beijerinck, M.W. Anhaufungsversuche mit Ureumbakterien. Centralblatt $f$. Bakteriologie II 7, 33-61 (1901).

8. Harder, W., Kuenen, J. \& Matin, A. Microbial selection in continuous culture. J. Appl. Micobiol. 43, 1-24 (1977).

9. Johnsen, A.R., Wick, L.Y. \& Harms, H. Principles of microbial PAHdegradation in soil. Environ. Pollut. 133, 71-84 (2005).

10. Wittebolle, L., Vervaeren, H., Verstraete, W. \& Boon, N. Quantifying community dynamics of nitrifiers in functionally stable reactors. Appl. Environ. Microbiol. 74, 286-293 (2008).

11. Whittenbury, R., Phillips, K. \& Wilkinson, J. Enrichment, isolation and some properties of methane-utilizing bacteria. Microbiology 61, 205-218 (1970).

12. Whiticar, M.J. Carbon and hydrogen isotope systematics of bacterial formation and oxidation of methane. Chem. Geol. 161, 291-314 (1999).

13. Reeburgh, W.S. \& Heggie, D.T. Microbial methane consumption reactions and their effect on methane distributions in freshwater and marine environments. Limnol. Oceanogr. 22, 1-9 (1977).

14. Welhan, J.A. \& Lupton, J.E. Light hydrocarbon gases in Guaymas Basin hydrothermal fluids: thermogenic versus abiogenic origin. AAPG Bull. 71, 215-223 (1987).

15. Proskurowski, G. et al. Abiogenic hydrocarbon production at lost city hydrothermal field. Science 319, 604-607 (2008).

16. Boetius, A. \& Wenzhofer, F. Seafloor oxygen consumption fuelled by methane from cold seeps. Nat. Geosci. 6, 725-734 (2013).

17. Rueter, P. et al. Anaerobic oxidation of hydrocarbons in crude oil by new types of sulphate-reducing bacteria. Nature 372, 455-458 (1994).

18. Boetius, A. et al. A marine microbial consortium apparently mediating anaerobic oxidation of methane. Nature 407, 623-626 (2000).

19. Laso-Pérez, R. et al. Thermophilic archaea activate butane via alkyl-coenzyme M formation. Nature 539, 396-401 (2016).

20. Rabus, R., Fukui, M., Wilkes, H. \& Widdle, F. Degradative capacities and $16 \mathrm{~S}$ rRNA-targeted whole-cell hybridization of sulfate-reducing bacteria in an anaerobic enrichment culture utilizing alkylbenzenes from crude oil. Appl. Environ. Microbiol. 62, 3605-3613 (1996).

21. Zengler, K., Richnow, H.H., Rossello-Mora, R., Michaelis, W. \& Widdel, F. Methane formation from long-chain alkanes by anaerobic microorganisms. Nature 401, 266-269 (1999). 
22. Meckenstock, R.U., Annweiler, E., Michaelis, W., Richnow, H.H. \& Schink B. Anaerobic naphthalene degradation by a sulfate-reducing enrichment culture. Appl. Environ. Microbiol. 66, 2743-2747 (2000).

23. Wang, L.-Y. et al. Characterization of an alkane-degrading methanogenic enrichment culture from production water of an oil reservoir after 274 days of incubation. Int. Biodeterior. Biodegrad. 65, 444-450 (2011).

24. Schink, B. Degradation of unsaturated hydrocarbons by methanogenic enrichment cultures. FEMS Microbiol. Ecol. 1, 69-77 (1985).

25. Rios-Hernandez, L.A., Gieg, L.M. \& Suflita, J.M. Biodegradation of an alicyclic hydrocarbon by a sulfate-reducing enrichment from a gas condensate-contaminated aquifer. Appl. Environ. Microbiol. 69 , 434-443 (2003).

26. Raghoebarsing, A.A. et al. A microbial consortium couples anaerobic methane oxidation to denitrification. Nature 440, 918-921 (2006).

27. McGlynn, S.E., Chadwick, G.L., Kempes, C.P. \& Orphan, V.J. Single cell activity reveals direct electron transfer in methanotrophic consortia. Nature 526, 531-535 (2015).

28. Jaekel, U. et al. Anaerobic degradation of propane and butane by sulfate-reducing bacteria enriched from marine hydrocarbon cold seeps. ISME J. 7, 885-895 (2013).

29. Jaekel, U., Vogt, C., Fischer, A., Richnow, H.-H. \& Musat, F. Carbon and hydrogen stable isotope fractionation associated with the anaerobic degradation of propane and butane by marine sulfate-reducing bacteria. Environ. Microbiol. 16, 130-140 (2014).

30. Kniemeyer, 0 . et al. Anaerobic oxidation of short-chain hydrocarbons by marine sulphate-reducing bacteria. Nature 449, 898-901 (2007).

31. Widdel, F. in Handbook of Hydrocarbon and Lipid Microbiology (ed. Timmis, K.N.) 3787-3798 (Springer, 2010).

32. Musat, F. \& Widdel, F. Anaerobic degradation of benzene by a marine sulfate-reducing enrichment culture, and cell hybridization of the dominant phylotype. Environ. Microbiol. 10, 10-19 (2008).

33. Tan, B. et al. Comparative analysis of metagenomes from three methanogenic hydrocarbon-degrading enrichment cultures with 41 environmental samples. ISME J. 9, 2028-2045 (2015).

34. Jaekel, U., Zedelius, J., Wilkes, H. \& Musat, F. Anaerobic degradation of cyclohexane by sulfate-reducing bacteria from hydrocarbon-contaminated marine sediments. Front. Microbiol. 6, 116 (2015).

35. Kleindienst, $\mathrm{S}$. et al. Diverse sulfate-reducing bacteria of the Desulfosarcina/Desulfococcus clade are the key alkane degraders at marine seeps. ISME J. 8, 2029-2044 (2014).

36. Krukenberg, V. et al. Candidatus desulfofervidus auxilii, a hydrogenotrophic sulfate-reducing bacterium of the HotSeep-1 cluster involved in the thermophilic anaerobic oxidation of methane. Environ. Microbiol. 18, 3073-3091 (2016).

37. Wegener, G., Krukenberg, V., Ruff, S.E., Kellermann, M.Y. \& Knittel, K. Metabolic capabilities of microorganisms involved in and associated with the anaerobic oxidation of methane. Front. Microbiol. 7 46 (2016).

38. Gieg, L.M., Duncan, K.E. \& Suflita, J.M. Bioenergy production via microbial conversion of residual oil to natural gas. Appl. Environ. Microbiol. 74, 3022-3029 (2008).

39. Holler, T. et al. Substantial $13 \mathrm{C} / 12 \mathrm{C}$ and $\mathrm{D} / \mathrm{H}$ fractionation during anaerobic oxidation of methane by marine consortia enriched in vitro. Environ. Microbiol. Rep. 1, 370-376 (2009).

40. Meulepas, R.J. et al. Enrichment of anaerobic methanotrophs in sulfate-reducing membrane bioreactors. Biotechnol. Bioeng. 104, 458-470 (2009).

41. Simoneit, B.R.T., Kawka, O.E. \& Brault, M. Origin of gases and condensates in the Guaymas Basin hydrothermal system (Gulf of California). Chem. Geol. 71, 169-182 (1988).

42. Teske, A. et al. The Guaymas Basin hiking guide to hydrothermal mounds, chimneys, and microbial mats: complex seafloor expressions of subsurface hydrothermal circulation. Front. Microbiol. 7, 75 (2016).

43. Cruse, A.M. \& Seewald, J.S. Low-molecular weight hydrocarbons in vent fluids from the Main Endeavour Field, northern Juan de Fuca Ridge. Geochim. Cosmochim. Acta 74, 6126-6140 (2010).

44. Riedel, C., Schmidt, M., Botz, R. \& Theilen, F. The Grimsey hydrothermal field offshore North Iceland: crustal structure, faulting and related gas venting. Earth Planet. Sci. Lett. 193, 409-421 (2001).
45. Jaeschke, A et al. Biosignatures in chimney structures and sediment from the Loki's Castle low-temperature hydrothermal vent field at the Arctic Mid-0cean Ridge. Extremophiles 18, 545-560 (2014).

46. Baker, E.T. \& German, C.R. On the global distribution of hydrothermal vent fields. in Mid-Ocean Ridges (eds. German, C.R., Lin, J. \& Parson, L.M.) 245-266 (Wiley, 2004).

47. Nauhaus, K., Boetius, A., Krüger, M. \& Widdel, F. In vitro demonstration of anaerobic oxidation of methane coupled to sulphate reduction in sediments from a marine gas hydrate area. Environ. Microbiol. 4, 296-305 (2002).

48. Wegener, G. et al. Biogeochemical processes and microbial diversity of the Gullfaks and Tommeliten methane seeps (Northern North Sea). Biogeosciences 5, 1127-1144 (2008).

49. Ruff, E.S. et al. Methane seep in shallow-water permeable sediment harbors high diversity of anaerobic methanotrophic communities, Elba, Italy. Front. Microbiol. 7, 374 (2016).

50. Holler, T. et al. Thermophilic anaerobic oxidation of methane by marine microbial consortia. ISME J. 5, 1946-1956 (2011).

51. Girguis, P.R., Cozen, A.E. \& DeLong, E.F. Growth and population dynamics of anaerobic methane-oxidizing archaea and sulfate-reducing bacteria in a continuous-flow bioreactor. Appl. Environ. Microbiol. 71, 3725-3733 (2005).

52. Jagersma, G.C. et al. Microbial diversity and community structure of a highly active anaerobic methane-oxidizing sulfate-reducing enrichment. Environ. Microbiol. 11, 3223-3232 (2009).

53. Aoki, M. et al. A long-term cultivation of an anaerobic methane-oxidizing microbial community from deep-sea methane-seep sediment using a continuous-flow bioreactor. PLoS One 9, e105356 (2014).

54. Orcutt, B.N. et al. Impact of natural oil and higher hydrocarbons on microbial diversity, distribution, and activity in Gulf of Mexico cold-seep sediments. Deep Sea Res. Part II Top. Stud. Oceanogr. 57, 2008-2021 (2010).

55. Sikkema, J., De Bont, J. \& Poolman, B. Mechanisms of membrane toxicity of hydrocarbons. Microbiol. Rev. 59, 201-222 (1995).

56. McAuliffe, C. Solubility in water of paraffin, cycloparaffin, olefin, acetylene, cycloolefin, and aromatic hydrocarbons1. J. Phys. Chem. 70, 1267-1275 (1966).

57. Edwards, E.A. \& Grbić-Galić, D. Complete mineralization of benzene by aquifer microorganisms under strictly anaerobic conditions. Appl. Environ. Microbiol. 58, 2663-2666 (1992).

58. Widdel, F. \& Bak, F. in The Prokaryotes Vol. 4 (eds. Trüper H.G., Balows A., Dworkin M., Harder W. \& Schleifer K.H.) 3352-3378 (Springer, 1992).

59. Brock, T.D. \& Od'ea, K. Amorphous ferrous sulfide as a reducing agent for culture of anaerobes. Appl. Environ. Microbiol. 33, 254-256 (1977).

60. Nauhaus, K., Albrecht, M., Elvert, M., Boetius, A. \& Widdel, F. In vitro cell growth of marine archaeal-bacterial consortia during anaerobic oxidation of methane with sulfate. Environ. Microbiol. 9, 187-196 (2007).

61. Wegener, G. \& Boetius, A. An experimental study on short-term changes in the anaerobic oxidation of methane in response to varying methane and sulfate fluxes. Biogeosciences 6, 867-876 (2009).

62. Deusner, C., Meyer, V. \& Ferdelman, T.G. High-pressure systems for gas-phase free continuous incubation of enriched marine microbial communities performing anaerobic oxidation of methane. Biotechnol. Bioeng. 105, 524-533 (2010).

63. Zhang, Y., Henriet, J.-P., Bursens, J. \& Boon, N. Stimulation of in vitro anaerobic oxidation of methane rate in a continuous high-pressure bioreactor. Bioresour. Technol. 101, 3132-3138 (2010).

64. Wankel, S.D. et al. Anaerobic methane oxidation in metalliferous hydrothermal sediments: influence on carbon flux and decoupling from sulfate reduction. Environ. Microbiol. 14, 2726-2740 (2012).

65. Cord-Ruwisch, R. A quick method for the determination of dissolved and precipitated sulfides in cultures of sulfate-reducing bacteria. Microbiol. Methods 4, 33-36 (1985).

66. Aeckersberg, F., Bak, F. \& Widdel, F. Anaerobic oxidation of saturated hydrocarbons to $\mathrm{CO}_{2}$ by a new type of sulfate-reducing bacterium. Arch. Microbiol. 156, 5-14 (1991).

67. Pawlak, Z. \& Pawlak, A.S. Modification of iodometric determination of total and reactive sulfide in environmental samples. Talanta 48, 347-353 (1999).

68. Grasshoff, K., Kremling, K. \& Ehrhardt, M. Methods of Seawater Analysis (Wiley, 2009). 